\title{
Numerical study on supersonic boundary-layer transition and wall skin friction reduction induced by fuel wall-jet combustion
}

\author{
Rui Xue ${ }^{\mathrm{a}, \mathrm{b}, * *}$, Xing Zheng ${ }^{\mathrm{a}, *}$, Lianjie Yue ${ }^{\mathrm{b}}$, Shikong Zhang ${ }^{\mathrm{c}}$, Chao Weng ${ }^{\mathrm{d}}$ \\ ${ }^{a}$ State Key Laboratory for Strength and Vibration of Mechanical Structures, Shaanxi Engineering Laboratory for Vibration Control of Aerospace Structures, School of \\ Aerospace, Xi'an Jiaotong University, 710049, Xi'an, People's Republic of China \\ ${ }^{\mathrm{b}}$ State Key Laboratory of High Temperature Gas Dynamics, Institute of Mechanics, Chinese Academy of Sciences, 100190, Beijing, People's Republic of China \\ ${ }^{\mathrm{c}}$ Xi'an Modern Control Technology Research Institute, 710065, Xi'an, People's Republic of China \\ ${ }^{\mathrm{d}}$ Tongii University, 200092, Shanghai, People's Republic of China
}

\section{A R T I C L E I N F O}

\section{Keywords:}

Compressible boundary layer combustion

Skin-friction reduction

Boundary layer transition

Transition $k-k l-w$ model

Hydrogen combustion

\begin{abstract}
A B S T R A C T
In this study, the effect of wall-jet combustion on boundary layer transition and skin friction reduction was numerically investigated. To effectively capture the characteristics of boundary layer flow, the transition $k-k l-w$ model was employed as the turbulence model and laminar finite-rate model was chosen as the combustion model. This numerical method was firstly validated by two sets of experimental results in open domain. After that, the research on wall-jet combustion was conducted and the numerical results showed that when injecting hydrogen in different directions, both the hydrogen self-ignition location and the skin friction on the wall were not altered significantly. When the injection angle to the airflow direction was increased to $30^{\circ}$, the intensity of combustion was insufficient and the skin-friction coefficient would be increased. Meanwhile, boundary layer transition occurred in a relatively smaller Reynolds number at this condition. The variation of the wall-jet height would have a greater impact on both boundary layer transition and the skin friction. More components can diffuse to the lower wall as the height of the wall-jet was enlarged, which can make the process of boundary layer transition be postponed and the skin friction be reduced as well. Furthermore, greater skinfriction reduction would be achieved downstream the self-ignition location when the wall was adiabatic, while the original Reynolds numbers for boundary layer transition is the smallest if the wall temperature is set to $600 \mathrm{~K}$. Finally, in order to simulate the effect of the back pressure on the combustion flow field, another injector is added near the exit at the upper wall to produce air-throttling flow jet. The results showed that altering back pressure nearly has little influence on boundary layer transition and the skin friction decreases with more airthrottling flow rate.
\end{abstract}

\section{Introduction}

Scramjet engines have been considered as one of the most appropriate propulsion systems for hypersonic air-breathing vehicles due to their high specific impulse in hypersonic speed. Hence, the development of scramjet engines attracts worldwide attention [1]. In order to promote the thrust-to-drag ratio that can make the engine into actual engineering application, previous researches have primarily focused on the methods of enhancing scramjet combustion efficiency, supersonic turbulent combustion [2], and flame stabilization [3] et al. However, studies on another way of promoting this ratio, like reducing the denominator, which is the skin-friction resistance, are presented and analyzed [4]. Generally, there are two main methodologies of drag reduction in the internal flow path of the engine. One is through modifying the configuration of the wall surface, such as ribs [5], pits [6,7], convex hulls et al. This is called passive method and has been widely used in various fields. The other methods, like plasma injection, film cooling and boundary layer combustion, etc. [8-10], are active drag reduction methodologies. Among numerous skin-friction reduction techniques, boundary layer combustion technique, which used gas like hydrogen injection and combustion by slot due to hydrogen has the advantages of wide flammability limit, fast flame propagation, and low ignition energy, has attracted worldwide attention due to its excellent skin-friction reduction performance [11,12].

The research history of compressible boundary layer combustion can be found in Ref. [13]. In these studies, the mechanism and factors

\footnotetext{
* Corresponding author.

** Corresponding author.

E-mail addresses: ruixue87@126.com (R. Xue), xingzhengya@126.com (X. Zheng).
} 


\begin{tabular}{|ll}
\hline Nomenclature \\
BSL & Baseline condition \\
$\mathrm{C}_{\mathrm{f}}$ & Skin friction coefficient \\
$\tau_{\mathrm{w}}$ & Wall skin-friction stress \\
$\rho$ & Inflow density \\
$\mathrm{U}$ & Inflow velocity
\end{tabular}

$\mathrm{T}$

$\mathrm{P}$

$\mathrm{H}$

$\delta_{1}$

$\delta_{2}$

$\mathrm{Re}_{\mathrm{x}}$
Inflow static temperature

Inflow static pressure

Shape Factor

Displacement thickness

Momentum thickness

Local Reynolds Number leading to the skin-friction reduction by boundary layer combustion have been considered, but the problem of boundary layer transition is not taken into account in these researches. However, precisely predicting hypersonic boundary layer transition, which greatly affects the skin friction, aerothermodynamics and flow quality in the flow channel, is of vital importance to the design of hypersonic vehicles. Moreover, according to the report of the Wendt [14] in Von Karmen Institute, accurately determining the transition position of the return compartment boundary layer can reduce the arrangement of the hypersonic aircraft heat-proof material, thereby reducing its total load by more than $20 \%$. In addition, relative research has shown that delaying the supersonic laminar boundary layer transition can greatly reduce the fuel consumption of supersonic aircraft $[15,16]$. Compared to incompressible flows, supersonic compressible flows involve more complex phenomena, including strong shock wave, strong compression effect, etc. Therefore, it is more necessary to consider boundary layer transition in the study of compressible flow. There are a large amount of theoretical, experimental and numerical simulation researches related to compressible boundary layer transition during the past several decades. Such as McDaniel [17], Papp [18], Fu [19], and Yang [20], based on the theory of flow stability, they constructed transition models and conducted numerical simulation of hypersonic transition flows, and finally obtained consistent results with those experiment results. Emmons [21] concluded that the place where the first turbulence spot appears is defined as the initial transition position, where the skin friction coefficient and wall heat transfer under high-speed flow begin to deviate from the laminar flow value. Turbulence spot has a welldefined shape, the internal fluid close to turbulence state and the surrounding is laminar flow state. Moreover, researchers have conducted a series of studies on the influence factors of compressible boundary layer transition. Softley [22] performed an experiment in Mach 10 conventional wind tunnel and found that when Mach number is large than 4, with the increase of Mach number, compressible effects make boundary layer more stable and transition position is delayed and transition Reynolds number increased. Pate's study [23] indicated that the influence of noise is dominant and leads to the advance of boundary layer transition in conventional hypersonic wind tunnels. Stetson's study [24] indicated that at the zero angle of attack, the transition can be delayed by a small blunt degree of the head, while the transition position can be advanced by a large blunt degree. Moreover, the influence of wall temperature on boundary layer transition is also studied, the results [25] indicated that the boundary layer may still be dominated by the first mode if environmental disturbance cannot excite Mack mode [26] in hypersonic flow, and lowering the wall temperature may delay the occurrence of transition because of the cold wall has a stabilizing effect on the first mode. Hao et al. [27] found that the windward side transition is related to the separation in the compression corner and large separation can cause earlier transition onset in boundary layer by analyzing the distributions of heat transfer rate on the X-51A forebody.

The aforementioned studies on compressible boundary layer transition are mostly based on cold flow. However, for flows which are characterized as great gradient like boundary layer or mixing layer, the heat release in the inner layer has a great influence on both the stability and the development of the flow. To investigate the effects, the experiment completed by Li [28] found that the gas flow speed is accelerated with the increase of heat release in the whole calculation region, and the gas disturbance increases obviously, which makes the thermal boundary layer thinner than that without heat addition. The experiment conducted by Stalker [29] indicates that the thickness of the boundary layer approaching the hydrogen injection station has a major effect on the boundary layer combustion process, and when boundary layer combustion occurs, it offers a promising means of controlling hypersonic turbulent skin friction. Yu [30] found that strong Stefan flow is formed at the fuel surface and the complex chemical reaction occurs in the boundary layer in combustion case, which has significant effects on the mass transfer. The computational results obtained by Carmignani [31] shows that when the flame propagates into boundary layer, its intensity strengthens, which is mainly reflected in its size, flame temperature, and spread rate. Similarly, the effect of heat release on movement characteristics of shock train in the boundary layer is numerically investigated by Zhang [32], where they found that the appearance and disappearance of high temperature gas by combustion heat release in the boundary layer result in the shock train shrinkage and stretch. Recently, Chen [33] conducted numerical investigation of combustion in three dimensional spatially developing supersonic mixing layers and the results indicated that the spatial distributions of flow, thermodynamic and component parameters are greatly different under different combustion conditions, which is related to the heat release and shock phenomenon in mixing layer. In addition, the simulation results also indicated that the mixing efficiency in mixing layer is affected mainly by incoming freestream condition and heat release. There are few researchers have analyzed the process of boundary layer transition under the condition of heat release. Madavan [34] conducted direct numerical simulation of the boundary layer transition on a heated plate and gave the computational results of transition to turbulence of the spatially evolving boundary layer in the presence of relatively high freestream turbulence. Pouransari [35] investigated the wall heat transfer and combustion regimes in a turbulent non-premixed wall-jet flame and concluded that the transition to turbulence is considerably delayed due to the heat-release induced effects and the overshoot of skin-friction coefficient in the transition point is reduced with the increase of heat release.

In summary, it can be concluded that the available experimental and numerical studies have all mostly focused on the variation of flow field and performance parameters in inner layer under the heat addition condition. However, few researches take into account the effect of heat release on boundary layer transition. As the effect of heat release in compressible boundary layer is quite important and the phenomena of boundary layer transition could not be ignored. In order to further investigate the boundary layer of combustor for skin-friction reduction, the study on the effect of heat release in compressible boundary layer on boundary layer transition and skin friction was carried out in this paper. Meanwhile, the Transition $k-k l-w$ turbulence model is employed to effectively capture the boundary layer transition process. Firstly, the effect of different wall-jet conditions like hydrogen injection angles and the slot heights are conducted. Then the variation of wall boundary conditions on the boundary layer flow was carried out. Finally, in order to explore the application of boundary layer combustion for skin-friction reduction in real scramjet combustor conditions, a port for injecting throttling flow was established near the exit of the flow path to investigate the effect of back pressure induced by main fuel combustion. Through the investigation, both the mechanism and basic 
influencing factors of boundary layer combustion could be better revealed, which is helpful for the proper understanding of boundary layer combustion for skin-friction reduction and boundary layer transition.

\section{Numerical methods and validation}

\subsection{Turbulence and chemistry modeling}

In order to study the effect of heat release on boundary layer transition and obtain accurate skin-friction drag results, the Transition $k-k l-w$ model is selected as the turbulence model. Transition $k-k l-w$ model is a three-equation eddy-viscosity type, which contains transport equations for turbulent kinetic energy $\left(k_{T}\right)$, laminar kinetic energy $\left(k_{L}\right)$ and the inverse turbulent time scale $(\omega)$ for simulating the boundary layer transition process. Note that the Transition $k-k l-w$ model uses inverse turbulent timescale $(\omega)$ rather than the dissipation rate $\varepsilon$. The transport equations are [36]:

$$
\begin{aligned}
\frac{D k_{T}}{D t}= & P_{k_{T}}+R+R_{N A T}-\omega k_{T}-D_{T}+\frac{\partial}{\partial x_{j}}\left[\left(\nu+\frac{\alpha_{T}}{\alpha_{k}}\right) \frac{\partial k_{T}}{\partial x_{j}}\right] \\
\frac{D k_{L}}{D t}= & P_{k_{L}}-R-R_{N A T}-D_{L}+\frac{\partial}{\partial x_{j}}\left[\nu \frac{\partial k_{L}}{\partial x_{j}}\right] \\
\frac{D \omega}{D t}= & C_{\omega 1} \frac{\omega}{k_{T}} P_{k_{T}}+\left(\frac{C_{\omega R}}{f_{W}}-1\right) \frac{\omega}{k_{T}}\left(R+R_{N A T}\right)-C_{\omega 2} \omega^{2}+C_{\omega 3} f_{\omega} \alpha_{T} f_{W}^{2} \frac{\sqrt{k_{T}}}{d^{3}} \\
& +\frac{\partial}{\partial x_{j}}\left[\left(\nu+\frac{\alpha_{T}}{\alpha_{\omega}}\right) \frac{\partial \omega}{\partial x_{j}}\right]
\end{aligned}
$$

As shown in Table 1, the 9-species, 27-reaction model established by Marinov [37] is adopted as the hydrogen/air reaction mechanism. Previous research has shown that the reaction mechanism is appropriate for simulating hydrogen combustion in supersonic flows [38] and the laminar finite-rate model is employed as the combustion model. So the reaction-rate constant is approximated by the Arrhenius Equation as the following:

$k=A T^{B} \exp (-E / R T)$

Where $\mathrm{A}$ is the pre-exponential collision frequency factor, $\mathrm{T}$ represents the temperature and B means the temperature exponent. $\mathrm{E}$ is the activation energy, and $\mathrm{R}$ represents the gas constant.

\subsection{Numerical schemes}

The governing equations will be solved using Fluent, a finite volume computational fluid dynamics code developed by ANSYS [36]. The reliability of this solver for supersonic flow-field simulation has been validated by a variety of studies [39-41]. The Advection Upstream Splitting Method (AUSM) was selected for the fluxes calculation. This method allows for exact resolution of contact and shock discontinuities. The Third-Oder Monotone Upstream-Centered Scheme (MUSCL) was used for spatial discretization of the scalars. The MUSCL scheme blends a central differencing scheme and a second-order upwind scheme, providing the potential to improve spatial accuracy and reduce numerical diffusion. During calculation, the time history of water mass flux at the outlet and the relative mass flow rate, $\left|\dot{m}_{\text {out }}-\dot{m}_{\text {in }}\right| / \dot{m}_{\text {in }}$, should remain almost unchanged when determining whether the simulation is converged.

\subsection{Validation}

\subsubsection{Cold flow validation}

To ensure the accuracy of the selected Transition $k-k l-w$ turbulence model, an experiment for cold flow boundary layer was firstly selected. This is a supersonic cavity test conducted in the Princeton
University $20 \times 20 \mathrm{~cm}$ High Reynolds Number Supersonic Wind Tunnel at a freestream Mach number of 2.92 and the unit Reynolds number is $6.7 \times 10^{7}$ [42]. A sketch of the test model is shown in Fig. 1. A turbulent boundary layer was initially formed on a flat plate and then separated over a sharp backward-facing step. The resulting free shear layer bridges the $25.4 \mathrm{~mm}$ deep cavity and reattaches to a flat ramp which is inclined $20^{\circ}$ to the horizontal direction. The airstream condition is shown in Table 2.

Both the Mach number contour and streamlines is shown in Fig. 2. It can be seen that the recirculation zone is formed in the cavity. Additionally, the pressure distribution along the lower wall is shown in Fig. 3. It could be seen that both the trend and the quantity are in good agreement with the experimental data. In addition, Fig. 4 compares the experimental skin-friction coefficient along the bottom wall with the simulation results. Basically, the simulation results captured the variation of the skin-friction along the wall. A relatively large discrepancy (within 20\%) in the value of skin-friction occurred at downstream. The reason for this discrepancy is that a separation zone is produced after the interaction between shock wave and the boundary layer. It is well known that boundary layer separation is hard to be accurately simulated through RANS method at present.

\subsubsection{Combustion flow validation}

Another combustion experiments conducted by Burrows and Kurkov $[43,44]$ is selected to check whether this simulation method could appropriately capture the combustion flow characteristics. Fig. 5 shows

Table 1

Rate constants for 9 species 27-step chemical kinetics of hydrogen [37].

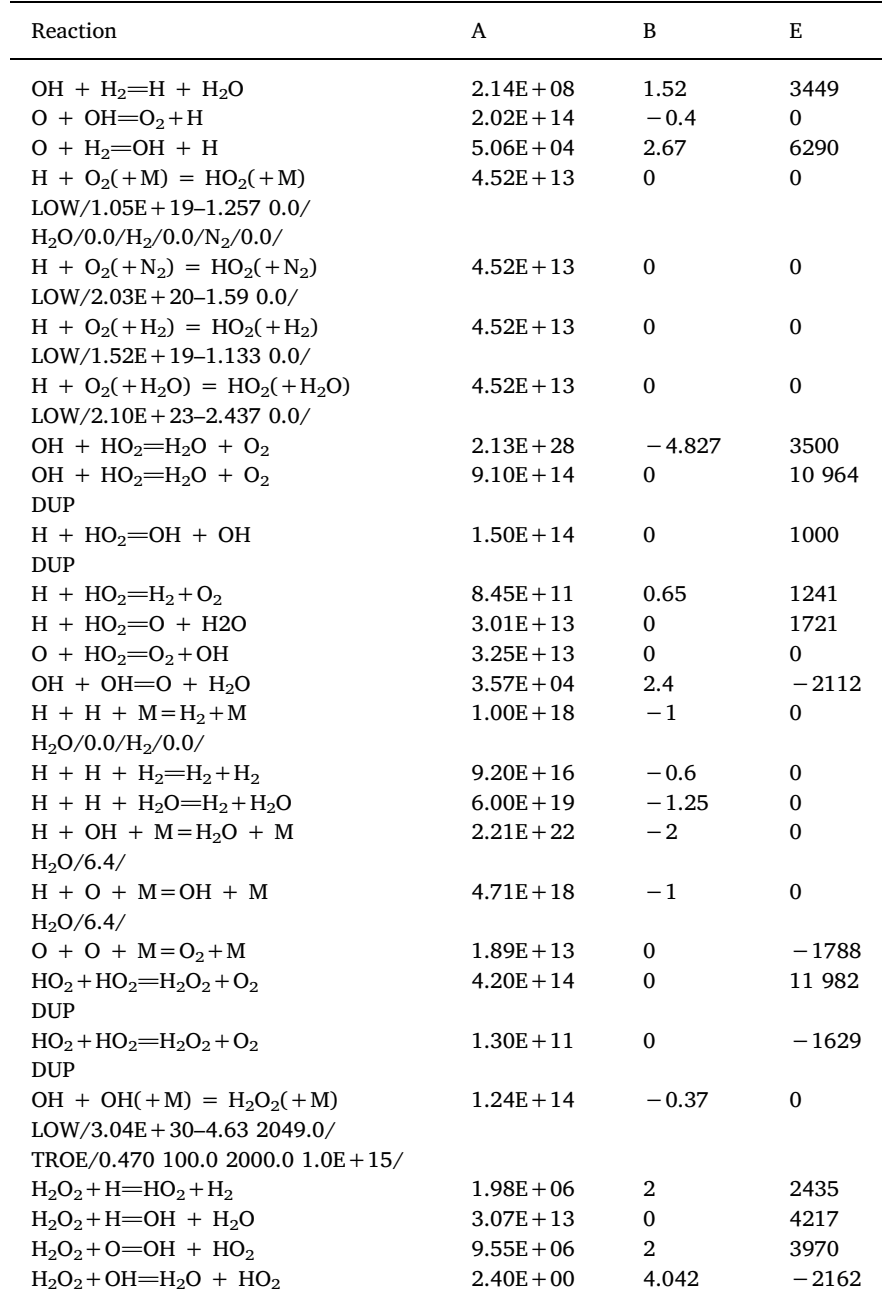




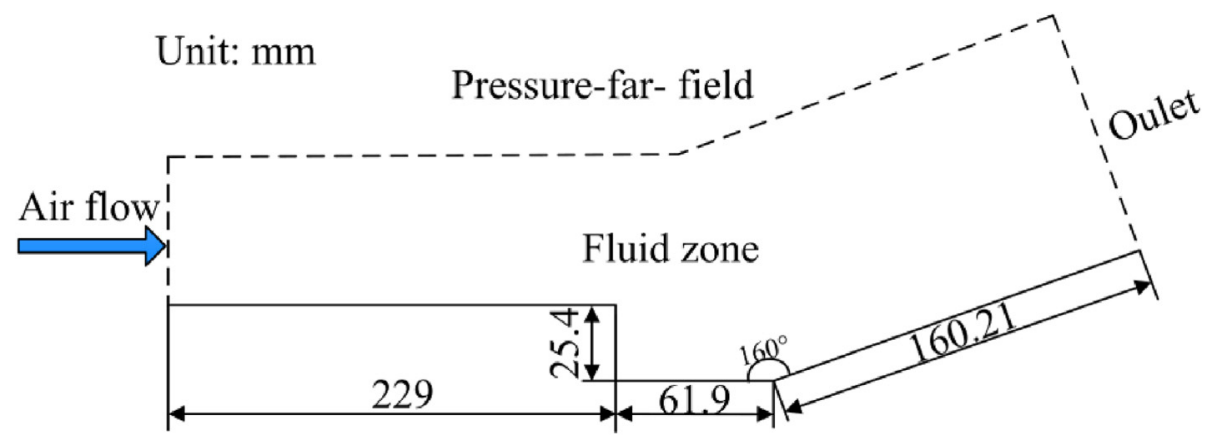

Fig. 1. Flow geometry and computational domain [42].

Table 2

Inflow conditions for the airstream.

\begin{tabular}{lllll}
\hline Parameter & $M a$ & $\mathrm{P} / \mathrm{Pa}$ & $\mathrm{T} / \mathrm{K}$ & $\mathrm{T}_{\text {wall }}$ \\
\hline Airstream & 2.92 & 21166.9 & 95.37 & adiabatic \\
\hline
\end{tabular}

the schematic of the experimental configuration. The height of the airstream entrance is $89 \mathrm{~mm}$ and hydrogen is injected parallel to the airstream from a slot installed after the backward step with a height of $4 \mathrm{~mm}[39,40]$. Hot, vitiated air enters the computational region at Mach 2.44 and mixes with the cold, pure hydrogen injected at sonic velocity. Thus, at some distance downstream of the slot, hydrogen will be self-ignited and a non-premixed flame is formed. The inflow conditions are shown in Table 3.

Figs. 6 and 7 show the numerical and experimental profiles for the Mach numbers and species mole fractions at the exit. The detailed flow field analysis is not illustrated here and the reader could refer [39] for more details. The comparisons between the computational and experimental results fully demonstrate that the models and corresponding numerical methods employed in this study can well reproduce the mixing and combustion process in boundary layer. Therefore, through the two validation cases, it can be concluded that the numerical simulation approach adopted in this paper is reliable and adequate to be used for investigating supersonic wall-jet combustion in this study.

\section{Analysis and discussion}

To investigate the influence of wall-jet combustion on boundary layer transition and skin friction, a configuration for numerical experiments is designed as shown in Fig. 8. In this combustion chamber, the height is $89 \mathrm{~mm}$ and the length is $1500 \mathrm{~mm}$. Hydrogen is injected into boundary layer through a fuel port at the height of $\mathrm{D}$ which will be

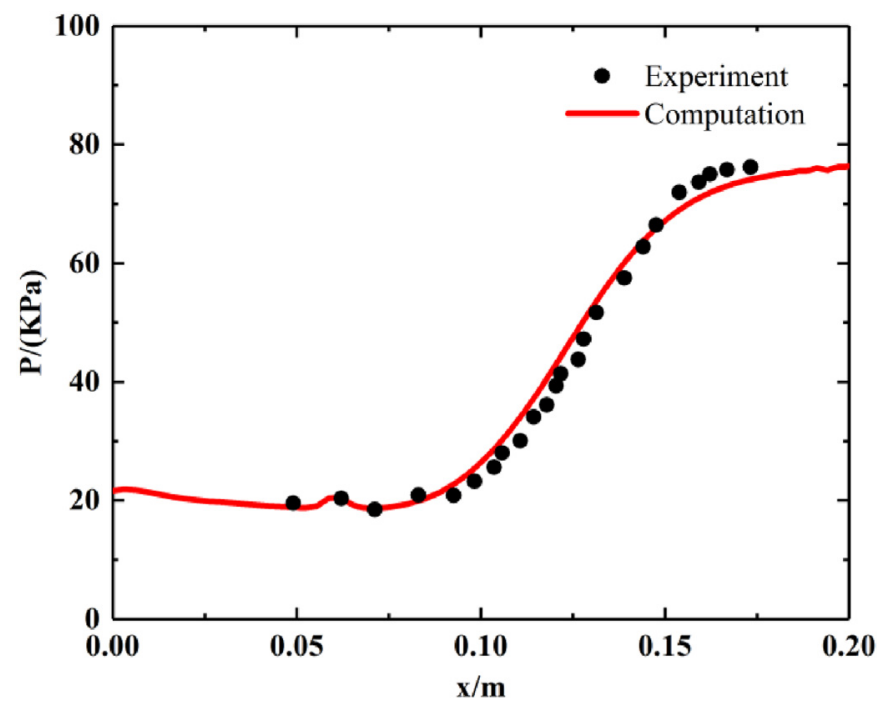

Fig. 3. Pressure distributions along the bottom wall.

altered in the subsequent analysis. The whole configuration and the corresponding meshes employed in this study are shown in Fig. 8. Moreover, the mesh contains 39102 structured grids and the resulting grid had a nominal $\mathrm{y}^{+}$of below 5 , which was deemed sufficient to model wall boundary layer effects in following numerical simulation.

As shown in Table 4, the cases that will be presented and discussed constitute a variation of the hydrogen injection and wall conditions like injection angle $\alpha$, injector height $\mathrm{D}$, and wall temperature $\mathrm{T}_{\text {wall }}$. Thus, the influence of different factors on wall-jet hydrogen combustion will be studied. At the baseline condition (BSL), the injection angle is $0^{\circ}$ (parallel to the airflow) and the injection height is $4 \mathrm{~mm}$. Two different

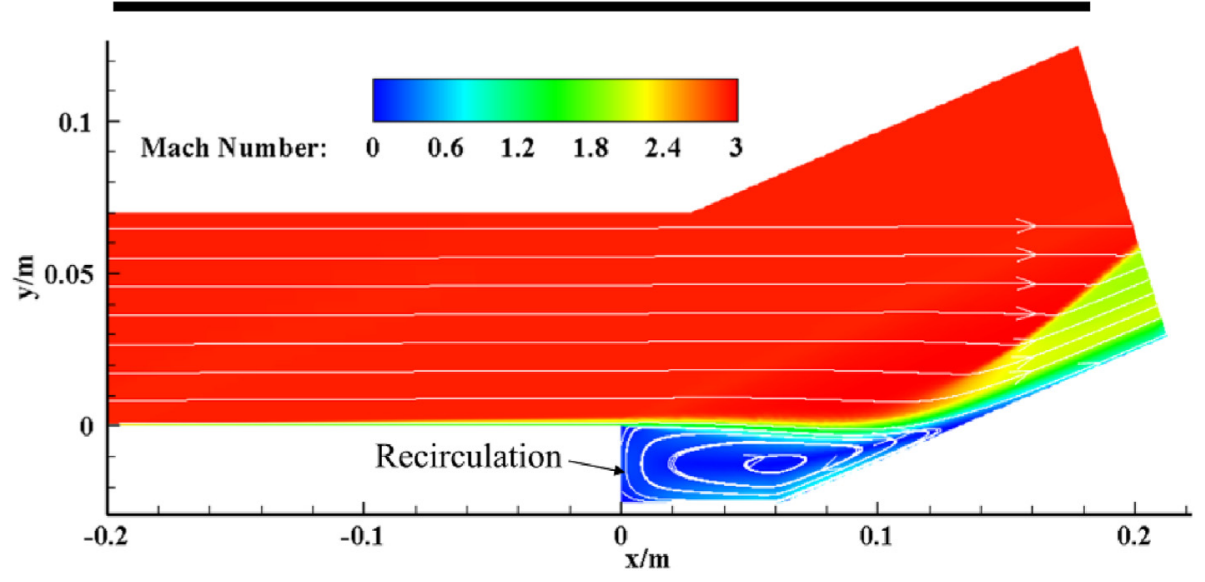

Fig. 2. Mach number contour and the streamline distribution. 


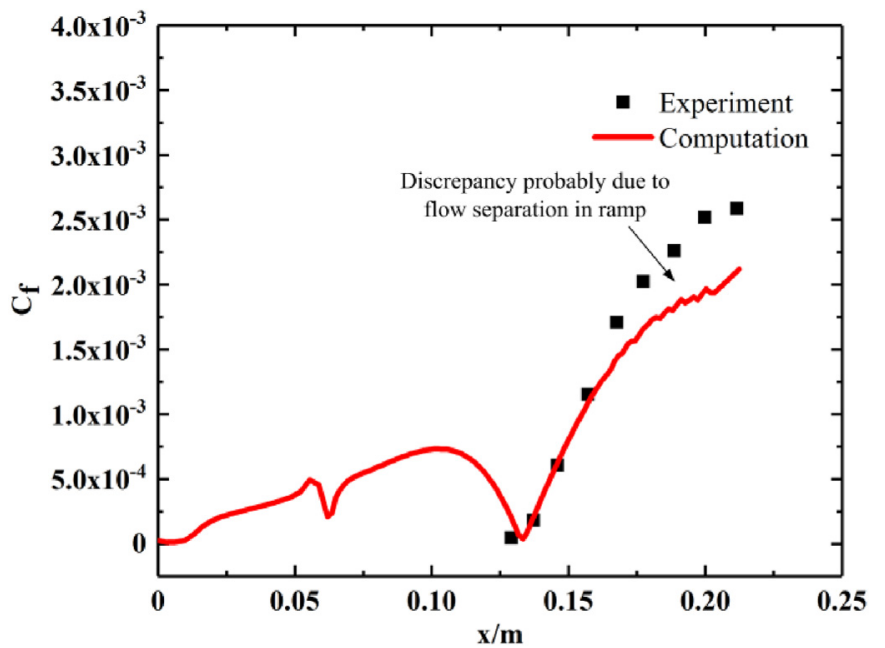

Fig. 4. Skin-friction coefficient distributions along the wall.

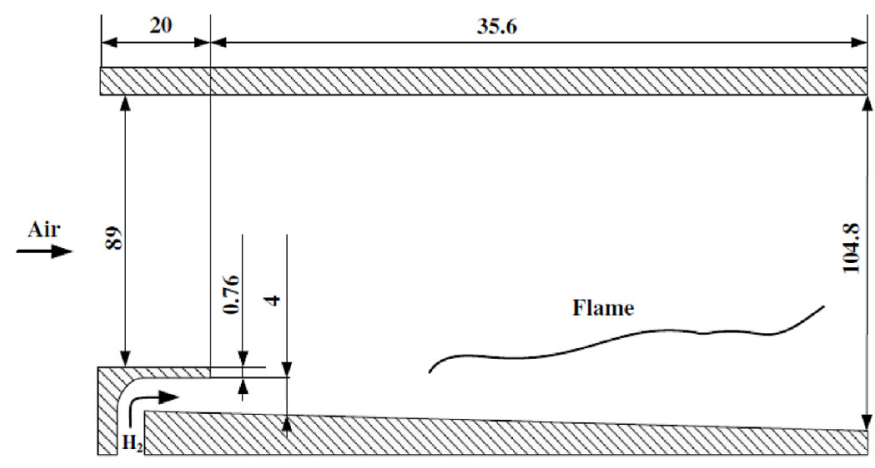

Fig. 5. Schematic of Burrows and Kurkov combustor [11].

Table 3

Inflow conditions for the airstream and injected hydrogen.

\begin{tabular}{|c|c|c|c|c|c|c|c|}
\hline Parameter & $M a$ & $\mathrm{~T} / \mathrm{K}$ & $\mathrm{P} / \mathrm{MPa}$ & $\mathrm{Y}_{\mathrm{O} 2}$ & $\mathrm{Y}_{\mathrm{H} 2}$ & $\mathrm{Y}_{\mathrm{N} 2}$ & $\mathrm{Y}_{\mathrm{H}_{2} \mathrm{O}}$ \\
\hline Airstream & 2.44 & 1270 & 0.1 & 0.258 & 0 & 0.486 & 0.256 \\
\hline Hydrogen & 1.0 & 254 & 0.1 & 0 & 1 & 0 & 0 \\
\hline
\end{tabular}

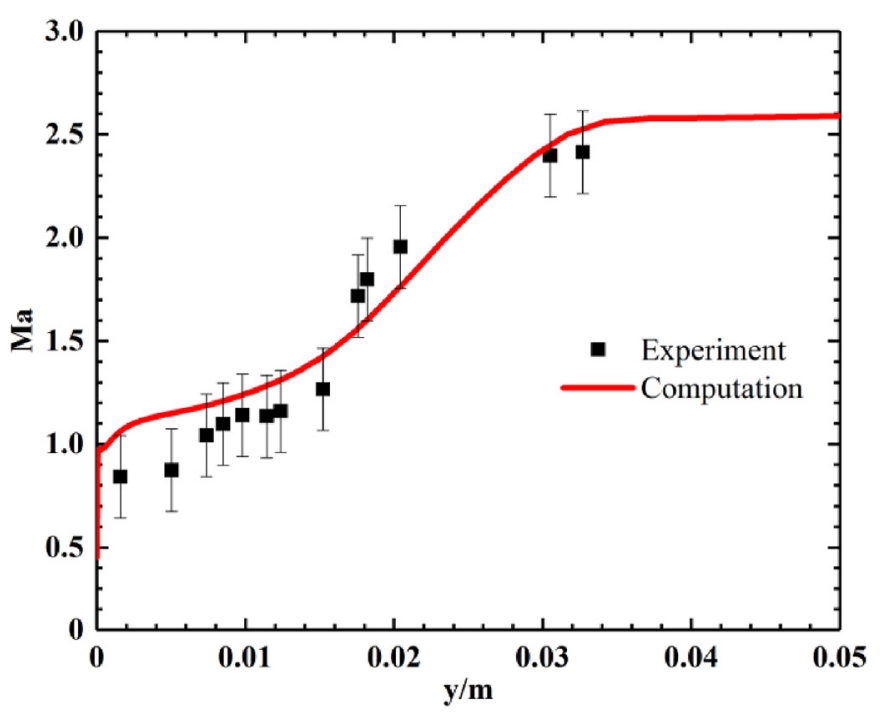

Fig. 6. Mach number distribution at the exit.

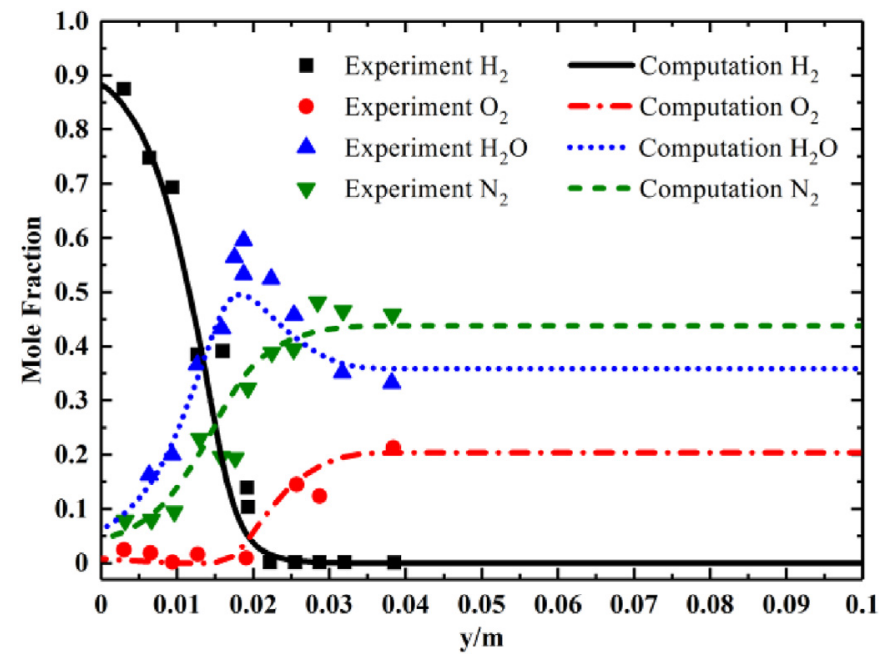

Fig. 7. Species mole fraction distributions at the exit.

injection angles to airflow direction $15^{\circ}$ and $30^{\circ}$ (Cases 1 and 2), and two other heights, $3 \mathrm{~mm}$ and $5 \mathrm{~mm}$ (Cases 3 and 4), are employed to study the influence of hydrogen injection geometries. Furthermore, two other cases, the adiabatic wall $\dot{\mathrm{q}}_{w}=0$ (Case 5) and $\mathrm{T}_{\text {wall }}=600 \mathrm{~K}$ (Case 6) are used to investigate the effect of wall condition.

Three different grids are selected for grid independent verification. The grid information is shown in Table $5 . \mathrm{N}$ and $\mathrm{y}_{1}$ in the table represents the number of grid cells and the height of the first layer grid, respectively.

The mass fraction of $\mathrm{H}_{2}$ along the lower wall is shown in Fig. 9. For the results of species distribution like $\mathrm{H}_{2}$, compared to medium and fine scale, there is a largest extent difference at $\mathrm{x}=0.7 \mathrm{~m}$ (nearly 23\%). However, which show the good consistency between medium and fine grid. It is clear that the variation of grid scale has great influence on results in the region near the wall. Hence, a medium grid is adopted in the subsequent numerical analysis, the final mesh contains 39102 structured grid.

\subsection{Effect of hydrogen injection angle}

The effect of different hydrogen injection angles is firstly investigated. Since the objective of this investigation is to study of skinfriction reduction and boundary layer transition, the first results presented are those of skin friction for the three different injection angles. Meanwhile, for boundary layer flow, the change of skin-friction coefficient is usually used as the indicator for boundary layer transition. In order to make comparisons, non-dimensionalized measures of skin friction are used. The skin friction coefficient is defined as:

$C_{f}=\frac{2 \tau_{w}}{\rho U^{2}}$

Where $\tau_{w}$ is the local wall skin-friction stress. $\rho$ and $U$ mean the density and velocity of the free airflow respectively.

Fig. 10 represents the distributions of skin-friction coefficient for different injection angles along the flow path and the local mainstream Reynolds number respectively. The variation of the frictional resistance is quite complicated as it fluctuates along the flow path. Near the hydrogen injection port, the skin-friction coefficient sharply declines. At $x=0.1 \mathrm{~m}$ where the self-ignition of the hydrogen fuel occurs, the value of skin-friction coefficient is reduced to the lowest point for both BSL and Case 1. Furthermore, it is known that for turbulent plate boundary layer flow without combustion, the skin-friction coefficient will be decreased along the flatbed because of the thickness of boundary layer increases. However, in Fig. 10 (a), it shows that the skin friction fluctuates and is not in the monotonically decreasing form. The reason for 


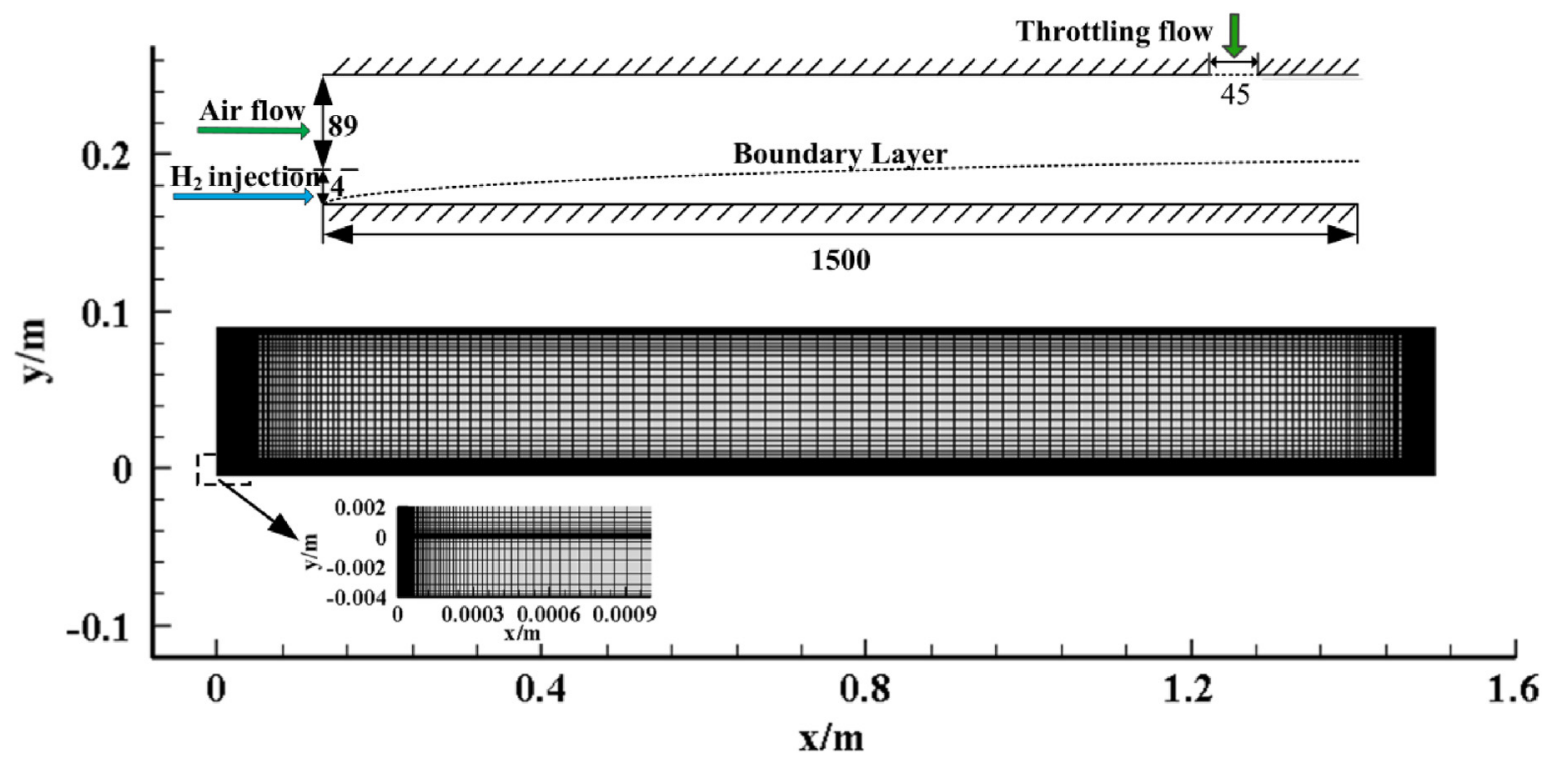

Fig. 8. The configuration and the computational grids.

Table 4

Numerical experimental items for Baseline and Cases 1-6.

\begin{tabular}{llllllll}
\hline Parameters & BSL & Case 1 & Case 2 & Case 3 & Case 4 & Case 5 & Case 6 \\
\hline$\alpha\left({ }^{\circ}\right)$ & 0 & $\mathbf{1 5}$ & $\mathbf{3 0}$ & 0 & 0 & 0 & 0 \\
$\mathrm{D}(\mathrm{mm})$ & 4 & 4 & 4 & $\mathbf{3}$ & $\mathbf{5}$ & 4 & 4 \\
$\mathrm{~T}_{\text {wall }}(\mathrm{K})$ & 300 & 300 & 300 & 300 & 300 & $\dot{\mathbf{q}}_{\boldsymbol{w}}=\mathbf{0}$ & $\mathbf{6 0 0}$ \\
\hline
\end{tabular}

Table 5

Meshes used to verify the grid independence.

\begin{tabular}{llll}
\hline Name & Coarse & Medium & Fine \\
\hline $\mathrm{N}$ & 14352 & 39102 & 59052 \\
$\mathrm{y}+$ & 3 & 1 & 1 \\
$\mathrm{y}_{1}$ & $10^{-5}$ & $10^{-6}$ & $10^{-6}$ \\
\hline
\end{tabular}

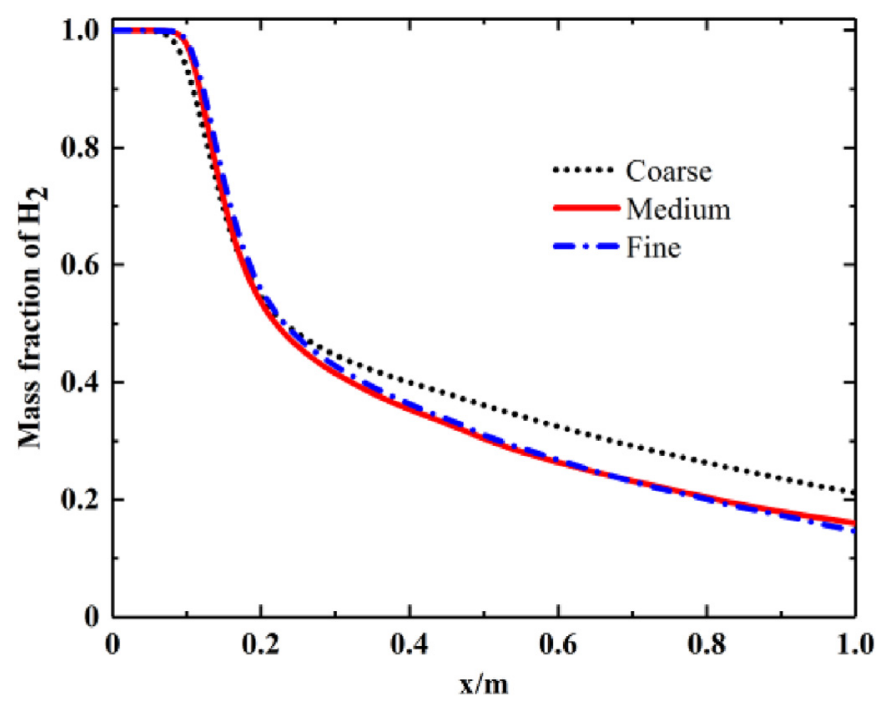

Fig. 9. Mass fraction of $\mathrm{H}_{2}$ of outlet for three grid solutions.

this is that when the shock waves intersect with the flame surface, the shock waves will be refracted to the lower wall. Then interaction between the refracted shock wave and boundary layer flow can lead separation occur. These can be clearly shown in Fig. 11. Thus, as shown in
Fig. 10 (a), at every contact point between the refracted shock waves and the boundary layer on the lower wall at the downstream of $x=0.4 \mathrm{~m}$, the skin-friction coefficient slightly increases, causing local fluctuation of skin-friction change along the flow path.

As shown in Fig. 10 (b), the corresponding region has been marked by dotted lines in Fig. 10 (a), when the hydrogen is injected from the leading edge of plate, the boundary layer flow is firstly in laminar. For the BSL condition, as the wall temperature is set constant to $300 \mathrm{~K}$ and the film-cooling effect plays a primary role near the hydrogen fuel injector, the skin-friction coefficient declines. From the plot, upstream the self-ignition location, where no combustion occurs, the fuel injection into the boundary layer is equivalent to film cooling. Meanwhile, lowtemperature hydrogen injection lowers the heat flux and skin friction significantly, which is a result of the film-cooling effect in region 1. Region 2 represents the frictional resistance in which boundary layer combustion plays the leading role. At $x=0.1 \mathrm{~m}$, when the local Reynolds number $\left(\mathrm{Re}_{\mathrm{x}}\right)$ reaches to $2.5 \times 10^{5}$, hydrogen in boundary layer is ignited and the self-ignition is like a 'perturbation source' in laminar boundary layer, which induces the starting of boundary layer transition. The computed data indicates onset of transition at roughly the same location as the self-ignition. In the transition region the computed skin friction increases rapidly and then follows the turbulent correlation. The skin-friction coefficient reaches to the maximum value at $x=0.2 \mathrm{~m}$ where the local Reynolds number is $1.1 \times 10^{6}$. After that, as the heat release from combustion in boundary layer can change the density distribution and increase the boundary layer thickness, the skin friction begins to decrease.

In order to investigate the wall heat transfer performance under the boundary layer combustion condition, Fig. 12 (a) shows the stagnation temperature in the first grid layer of the computational measurement under different injection angles conditions. Fig. 12 (b) shows the wall heat transfer rate of the computational results. The heat transfer rate shows the same trend with the stagnation temperature when transition occurs, heat transfer is nearly zero in laminar region because wall temperature is almost exactly laminar recover temperature. The momentum in the boundary layer leads to large regions of high wall heat transfer in the transitional region. The first position where the heat transfer rate departs from the laminar at $x=0.1 \mathrm{~m}$, the second position where the heat transfer rate has a sudden slow rise at about $x=0.2 \mathrm{~m}$. So heat transfer rate is also adopted to identify the transition onset in this case.

Furthermore, in boundary layer theory, boundary layer thickness 


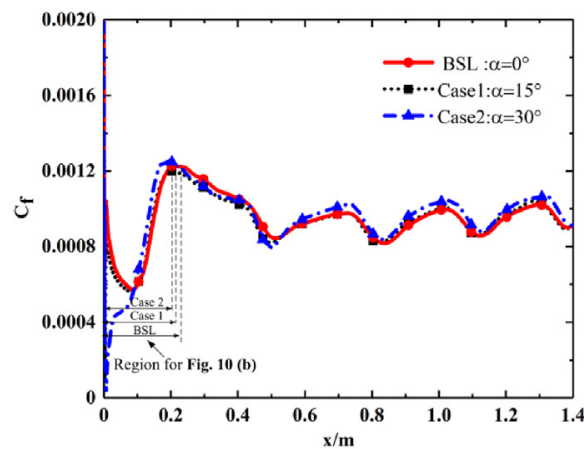

(a)

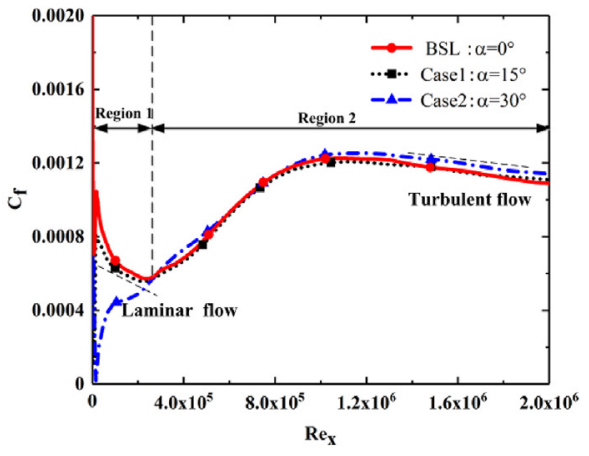

(b)

Fig. 10. Comparisons of $C_{f}$ for different injection angles: (a) along the flow path (b) $C_{f} v s \operatorname{Re}_{x}$.

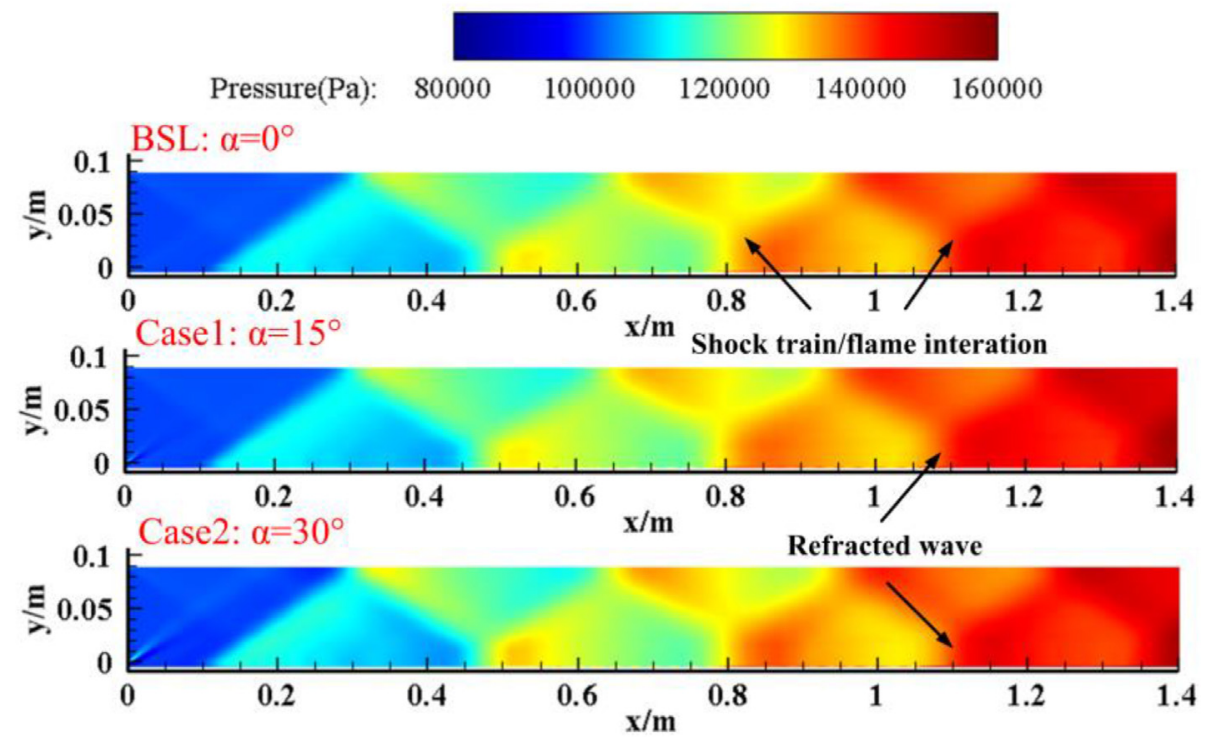

Fig. 11. Pressure contours for different injection angles.

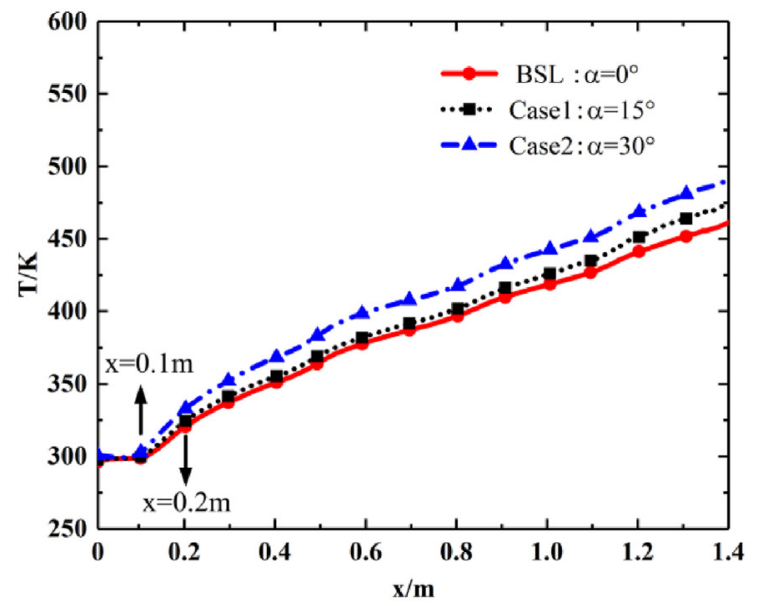

(a)

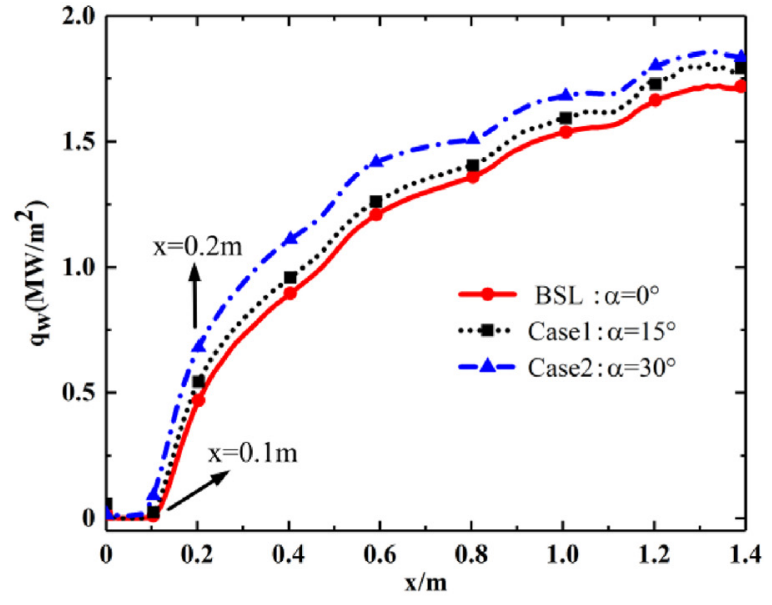

(b)

Fig. 12. Comparisons of stagnation temperature in the first grid layer (a) and heat flux (b) for different injection angles. 


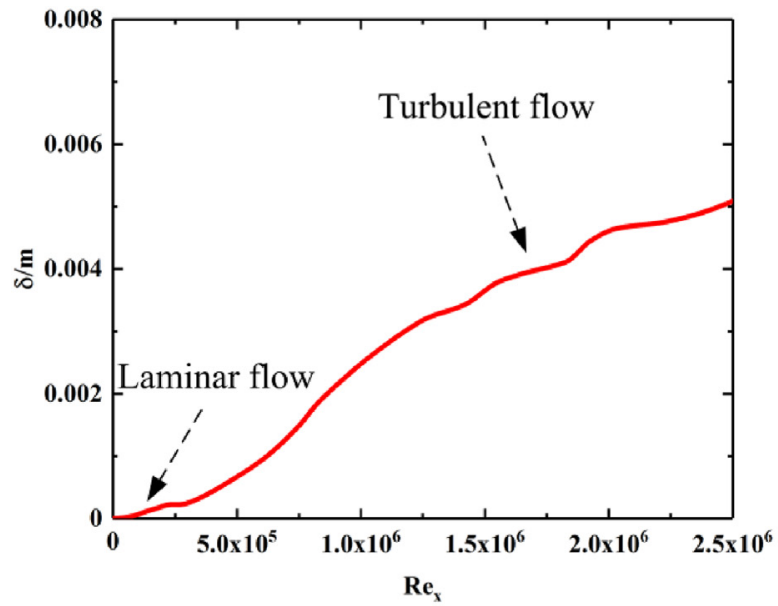

(a)

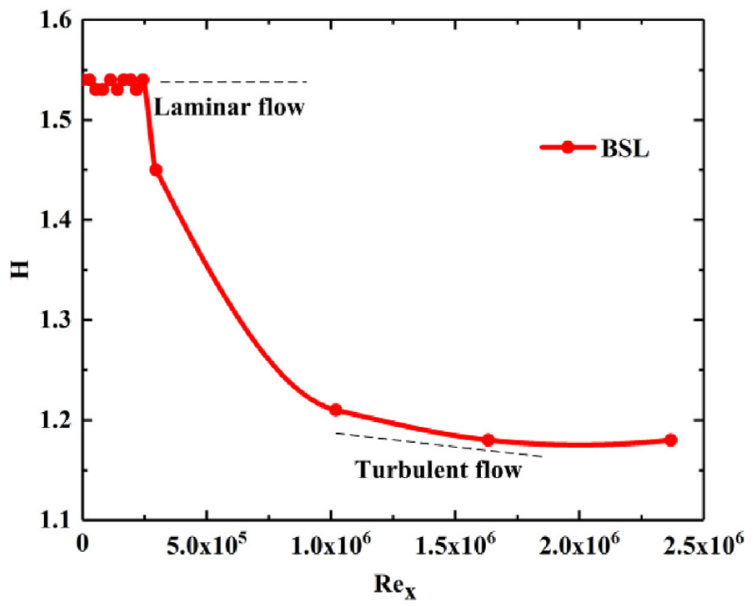

(b)

Fig. 13. Variation of boundary layer thickness (a) and shape factor (b) $v s \operatorname{Re}_{x}$ for BSL condition.

and the shape factor, $\mathrm{H}$, are usually used to characterize the occurrence of transition [45]. The location where $U=0.99 U_{\infty}$ is defined as the boundary layer edge in this paper and the development of the boundary layer thickness in the streamwise direction at the BSL condition is shown in Fig. 13 (a).

The definition of the shape factor is as the following:

$H=\frac{\delta_{1}}{\delta_{2}}$

$\delta_{1}$ is displacement thickness and $\delta_{2}$ represents the momentum thickness. The expressions of $\delta_{1}$ and $\delta_{2}$ are

$\delta_{1}=\int_{0}^{\delta}\left(\rho / \rho_{r e f}\right)\left(1-u / U_{r e f}\right) d y$

$\delta_{2}=\int_{0}^{\delta}\left(\rho / \rho_{r e f}\right)\left(u / U_{r e f}\right)\left(1-u / U_{r e f}\right) d y$

The shape factor $\mathrm{H}$ is the ratio of displacement thickness to momentum thickness, which represents the shape of the average velocity profile in the boundary layer. Generally, the turbulent boundary layer shape factor $\mathrm{H}$ is smaller than laminar flow. Thus, in order to inspect whether the above explanation for the mechanism of the skin-friction change is reasonable, the variation of the shape factor at the BSL condition is shown in Fig. 13 (b).

In the laminar flow region, the boundary layer thickness increases slowly, until $x=0.1 \mathrm{~m}$, transition occurs in the flow, and the boundary layer thickness increases rapidly. When transition is completed, the growth rate of the boundary layer thickness becomes increases slowly again. Here the position where the boundary layer thickness departs from the laminar value is defined as the transition onset.

From Fig. 13 (b), It could be seen that from the leading edge to $x=0.1 m\left(\operatorname{Re}_{\mathrm{x}}=2.5 \times 10^{5}\right)$, the shape factor is kept constant to the value of about 1.54, which means the boundary layer flow is laminar in this region. Then the shape factor begins to decrease at the downstream of $x=0.1 \mathrm{~m}$, indicating that boundary layer transition starts. Until $\mathrm{Re}_{\mathrm{x}}$ reaches as high as $1.7 \times 10^{6}$, the transition process is completed and the boundary layer becomes turbulent. If the injection angle is quite large, such as in Case 3 for $\alpha=30^{\circ}$, the transition starting position can move upstream to near the leading edge of the flatbed. Thus, the boundary layer transition starts quite early and the region of boundary layer transition is longer at this condition than that of other injection angles.

In order to further prove that the selected turbulent transition $k-k l-w$ model is applicable to capture laminar flow, the boundary layer region perpendicular to the streamwise at $x=0.05 \mathrm{~m}$ is selected for the BSL.

Fig. 14 shows computed mean velocity profiles obtained at various streamwise locations. The dashed line represent the linear relationship $\mathrm{u}_{+}=\mathrm{y}_{+}$and dot dashed line represent the logarithmic law of the wall $\mathrm{u}_{+}=2.5 \ln \mathrm{y}_{+}+5.0$. The computed velocities gradually change from laminar to the turbulent. From the plot, the variation tendency of velocity in the boundary layer at $x=0.05 \mathrm{~m}$ is in good agreement with the theoretical value of the laminar flow. In addition, this paper puts emphasis on the prediction of transition onset. So the transition model can be used to capture laminar flow, which further proves the effectiveness of the model to simulate boundary layer transition.

\subsection{Effect of hydrogen fuel injection heights}

Then the variation of the slot height is studied. Fig. 15 represents the distributions of skin-friction coefficient for different injector heights along the flow path and the local mainstream Reynolds number respectively. Obviously, the variation of the injector height can significantly affect the boundary layer transition onset. As illustrated in

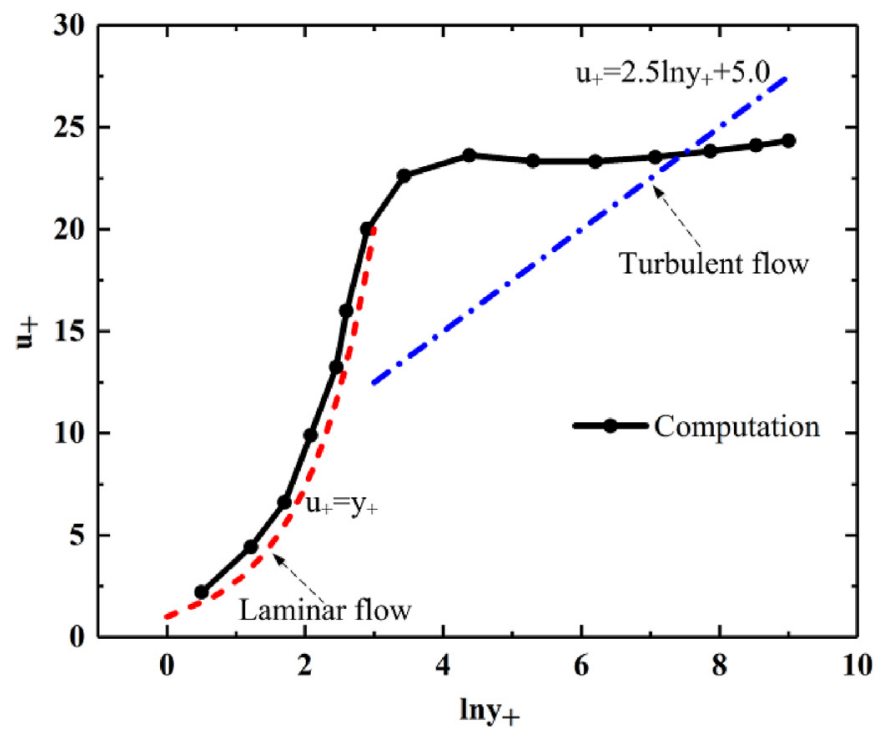

Fig. 14. Mean velocity distribution in the boundary layer at $x=0.05 \mathrm{~m}$. 


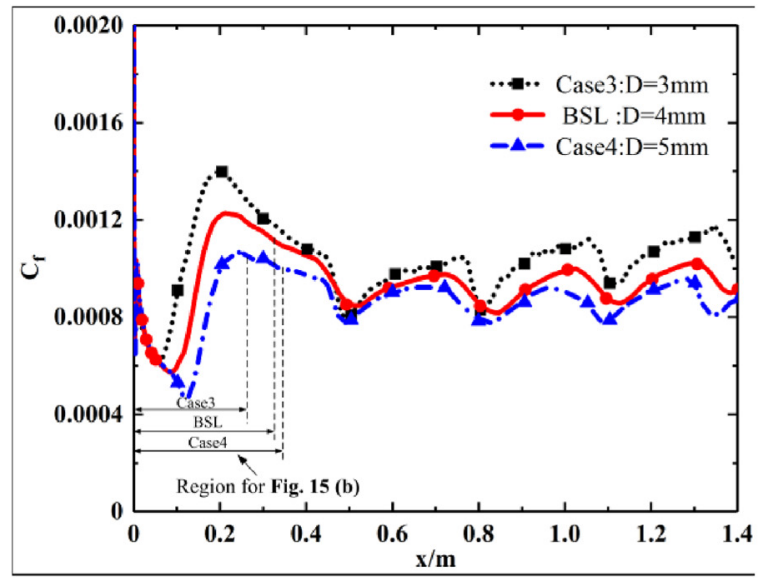

(a)

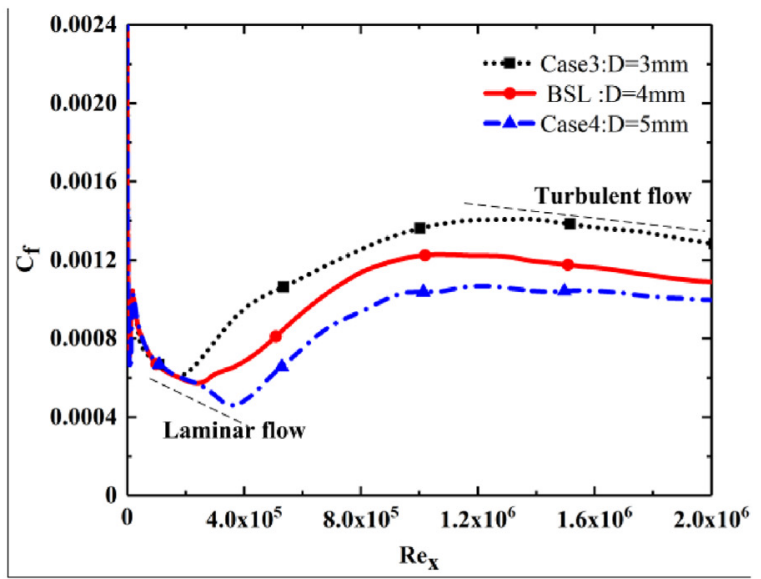

(b)

Fig. 15. Comparisons of $C_{f}$ for different injector heights: (a) along the flow path (b) $C_{f} v s \operatorname{Re}_{x}$.

Ref. [11], the distances between the flame and the lower wall could be modified with the variation of the hydrogen fuel injector heights. When the flame moves towards to the wall with lower injector height, the perturbation induced by self-ignition can be 'felt' earlier in boundary layer flow. Thus, the origin of boundary layer transition occurs at more upstream as the height of hydrogen fuel injector decreases. So for Case 3 with $\mathrm{D}=3 \mathrm{~mm}$, the transition starts at about $x=0.05 \mathrm{~mm}$ and for Case 5 with $D=5 \mathrm{~mm}$, it moves downstream to about $x=0.14 \mathrm{~mm}$. For Case 4 , at $\mathrm{x}=0.12 \mathrm{~m}$ the skin friction begins to depart from the laminar value and quickly approaches and exceeds the turbulent value. The overshoot beyond the fully turbulent value persists from $x=0.14$ until $x=0.24 \mathrm{~m}$. After $x=0.24 \mathrm{~m}$, the skin friction coefficient did not jump or drop obviously but still fluctuated slightly. These fluctuations are most likely due to flow features which are caused by the interaction between flames with shock wave.

In addition, as illustrated in Fig. 15 (a), the increase of the injector height is benefit for skin-friction reduction. The primary reason for this is that the thickness of the boundary layer can be enhanced when the injector height increases. Although the positions of self-ignition for these three conditions are different in the mainstream direction, the corresponding positions of the intersection between the shock train and the flame are similar, which also means the positions of fluctuating points are almost consistent. Furthermore, larger thickness of boundary layer can make the strength of the refracted shock waves weaker when they arrive near the lower wall. So the extent of boundary layer separation will be reduced, which can limit the increase of the skin friction at the downstream of every refracted shock wave. Besides, more heat release brought by larger injector height can make the flow density on the wall reduced and restrain the turbulent transport within the boundary layer, which can further reduce the skin friction.

In order to further analyze the changes of boundary layer thickness of different injector heights, the boundary layer thickness is assessed in the part. Fig. 16 (a) represents the velocity magnitude contour, the blue solid line representing the edge of the boundary layer where the velocity is equal to $99 \%$ of the air freestream velocity. Fig. 16 (b) represents the variation of boundary layer thickness. From the plot, it is not difficult to find that the boundary layer thickness increases with the increase of wall-jet. As can be seen from Fig. 16 (b), the boundary layer grows slowly before $x=0.1 \mathrm{~m}$, and transition occurs at $x=0.1 \mathrm{~m}$. The boundary layer thickness increases rapidly until $x=0.2 \mathrm{~m}$, when it enters the complete turbulent region, and the growth becomes slow again.

Unlike the results for the change of hydrogen fuel injection angles, the variation of injector height can effectively alter the strength of shock train, the boundary layer thickness would be influenced by shock waves. Fig. 17 (a) shows the exit temperature profiles of perpendicular
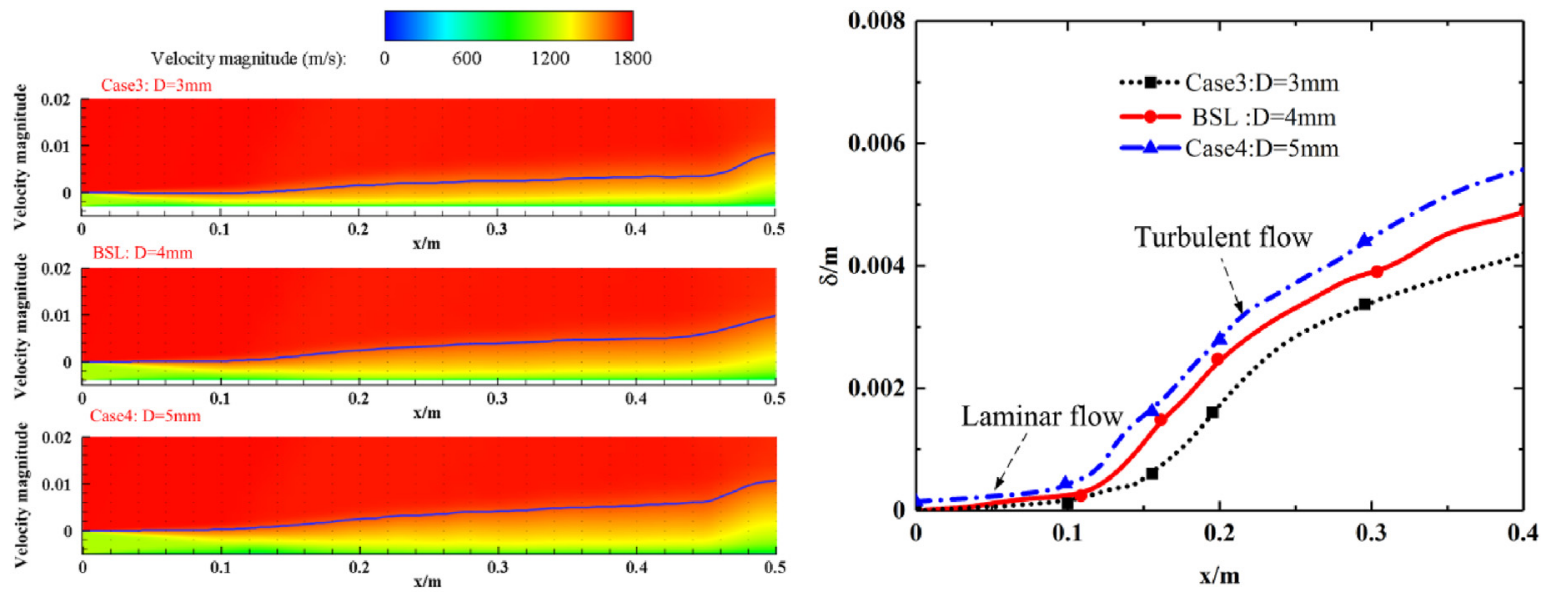

(a)

(b)

Fig. 16. Velocity magnitude contours (a) and variation of boundary layer thickness (b) for different injector heights. 


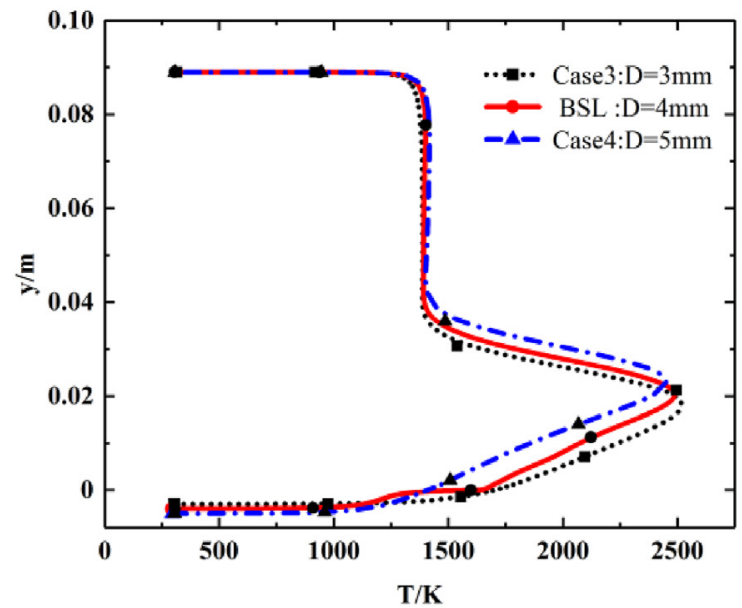

(a)

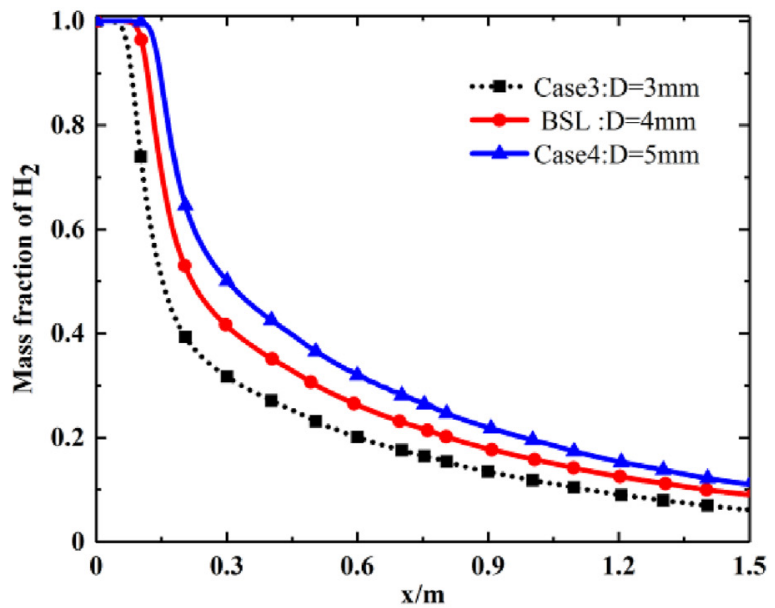

(b)

Fig. 17. Outlet temperature profiles (a) and Mass fraction of $\mathrm{H}_{2}$ (b) along the lower wall for different injector heights.

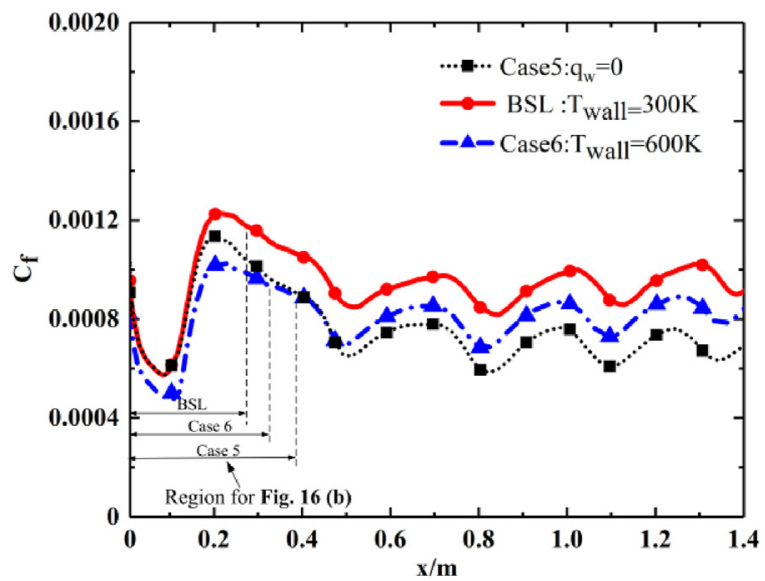

(a)

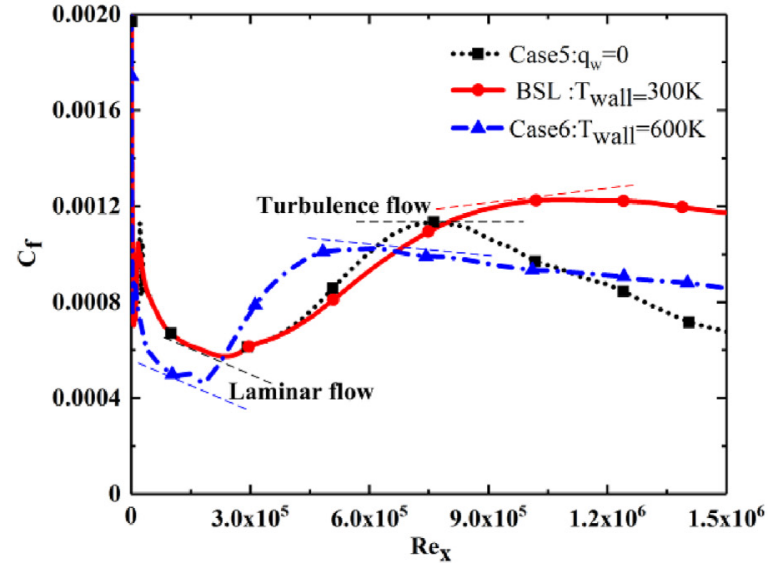

(b)

Fig. 18. Comparisons of $C_{f}$ for different wall conditions: (a) along the flow path (b) $C_{f} v s \operatorname{Re}_{x}$.

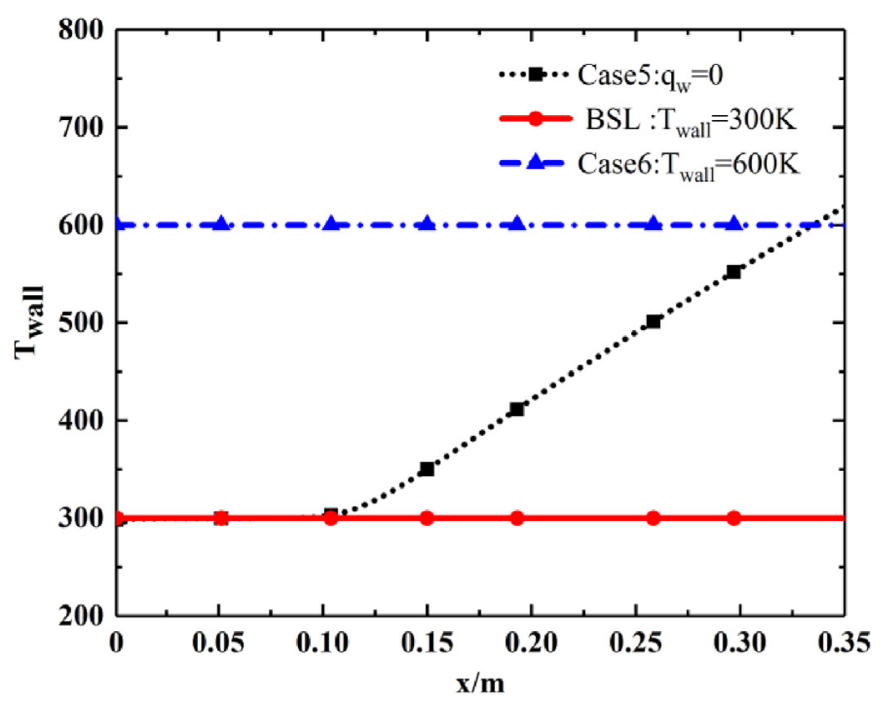

Fig. 19. Comparisons of bottom wall temperature for different wall heat transfer conditions.
Table 6

Inflow conditions for the throttle orifice.

\begin{tabular}{llllll}
\hline Parameters & $\mathrm{D}(\mathrm{mm})$ & $\alpha\left(^{\circ}\right)$ & $\mathrm{T}_{\text {wall }}(\mathrm{K})$ & $\dot{\mathrm{m}} \_$in $(\mathrm{kg} / \mathrm{s})_{1}$ & P_in(MPa) \\
\hline Case 7 & 4 & 0 & 300 & $\mathbf{2}$ & 0.3 \\
Case 8 & 4 & 0 & 300 & $\mathbf{3}$ & 0.3 \\
\hline
\end{tabular}

to the exit. The width of the temperature zone indicates the thickness of the flame, and it can be seen that the intensity of combustion is the largest under Case 4 . The hydrogen mass fraction along the bottom wall at different injector heights is shown in Fig. 17 (b). From Fig. 17 (b), the mass fraction of $\mathrm{H}_{2}$ near the wall can only be maintained within a small region after injection, and cannot be maintained uniformly for a long distance. Then, it begins to diminish and continues to be near the 0.1 at the exit. In addition, although the mass fraction of $\mathrm{H}_{2}$ for the Case 4 is not the smallest at the outlet, it has a large high-temperature zone due to abundant hydrogen fuel being injected into the boundary layer. As the hydrogen fuel injecting Mach number is kept constant $(M a=1)$, the increase of the hydrogen fuel injector height means more hydrogen will be injected into the combustion chamber. Thus, both the combustion intensity and the compression of the hydrogen fuel to the 


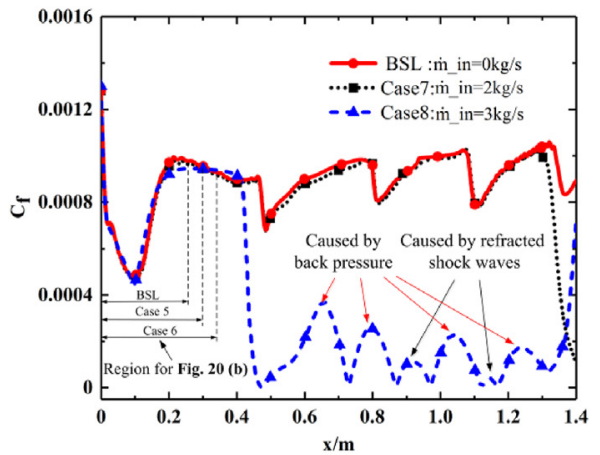

(a)

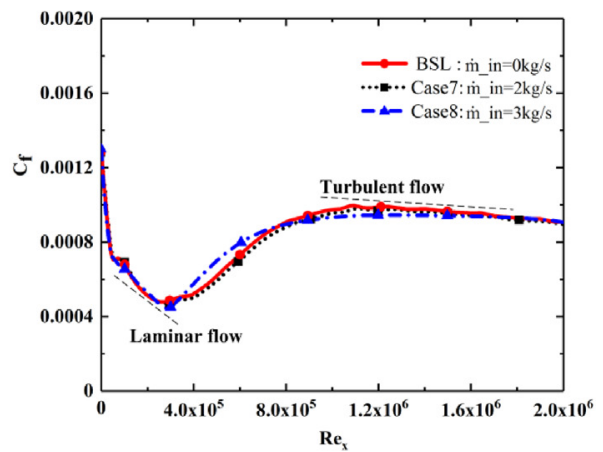

(b)

Fig. 20. Comparisons of $C_{f}$ for different throttle-flow: (a) along the flow path (b) $C_{f} v s R_{x}$.

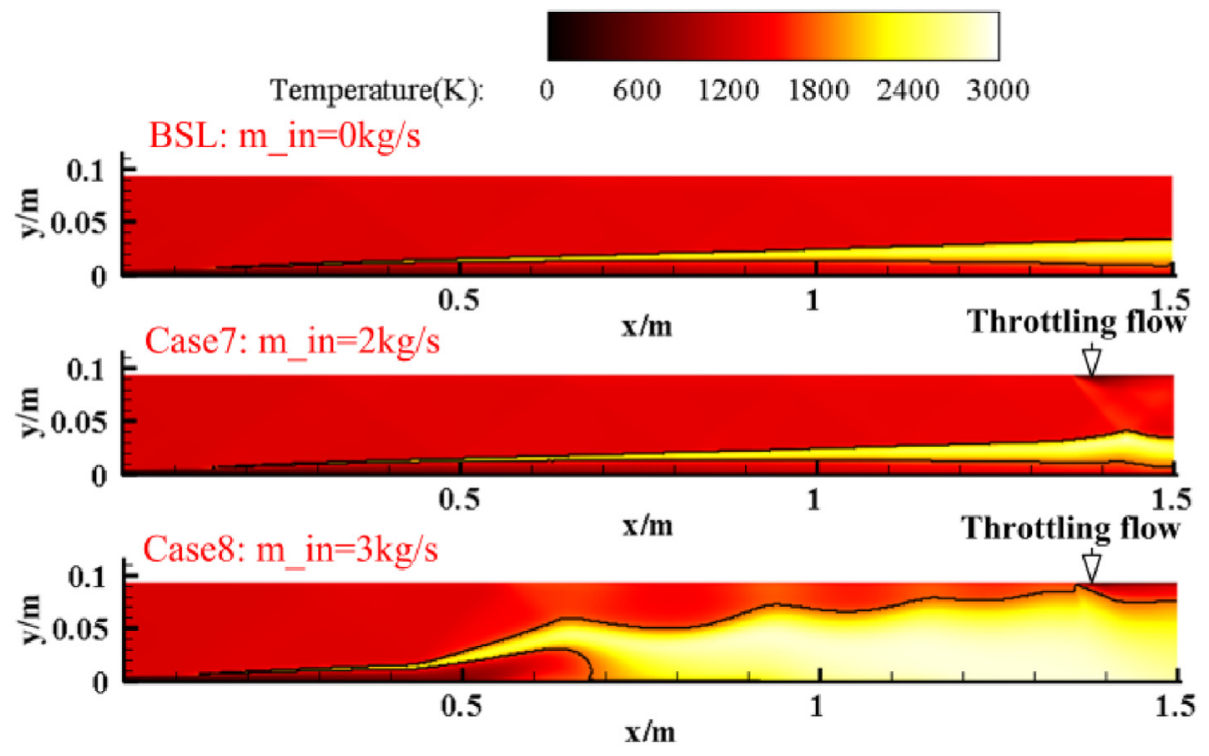

Fig. 21. Temperature contours for different throttle-flow.

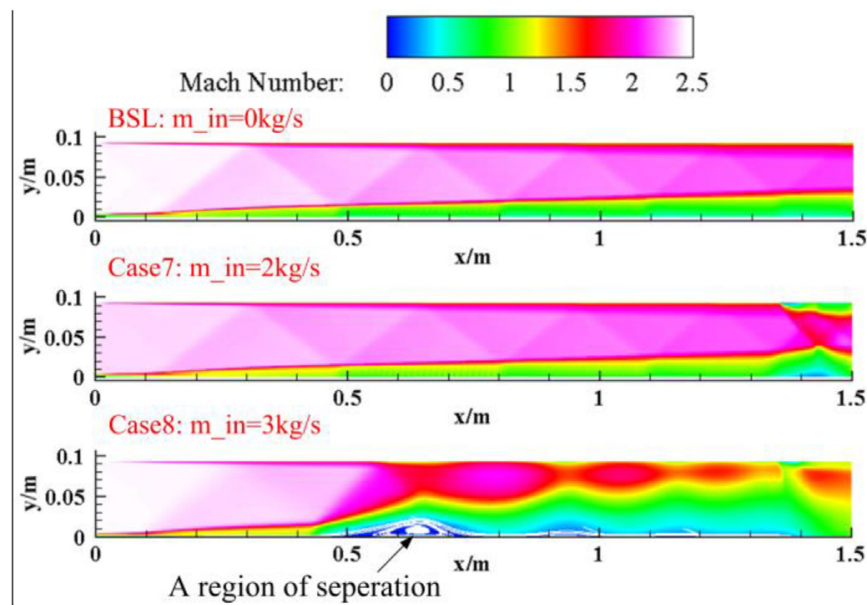

Fig. 22. Mach number contours for different mass flow rates of throttling flow.

airflow will be increased, which is benefit for the augment of the shock train strength, which ultimately affects the change in boundary layer thickness.

\subsection{Effect of wall temperature}

The heat transfer between boundary layer and the wall have significant influence on boundary layer flow. Thus, another two cases, which are adiabatic wall $\left(\dot{\mathrm{q}}_{w}=0\right)$ and $\mathrm{T}_{\text {wall }}=600 \mathrm{~K}$ are employed to investigate the effects of different wall heat-transfer conditions.

Fig. 18 shows the variation of skin-friction coefficient at different wall heat-transfer conditions along the flow path and the local mainstream Reynolds number respectively. It can be seen that from the region in $0<\mathrm{x}<0.2 \mathrm{~m}$, the change of skin-friction coefficient at BSL condition $\left(\mathrm{T}_{\text {wall }}=300 \mathrm{~K}\right)$ is almost the same to that of adiabatic wall condition. As the temperature of hydrogen is $254 \mathrm{~K}$, when the temperature of the wall is set as $300 \mathrm{~K}$, the temperature difference between boundary layer and the wall is quite small. Thus, in the range of $0<\mathrm{x}<0.2 \mathrm{~m}$ where the impact of combustion is insignificant and the film-cooling effect plays a leading role, the amount of heat transfer between boundary layer and the wall is small and can be approximated as an adiabatic wall condition. At the downstream of $x=0.2 \mathrm{~m}$, the heat-transfer increase to the wall induced by combustion is lower for BSL condition than that of the adiabatic wall condition. So the flow density in boundary layer is higher and the boundary layer is thinner at BSL condition compared to the adiabatic wall condition, which makes the skin friction higher in this region at BSL condition.

Oppositely, for the $\mathrm{T}_{\text {wall }}=600 \mathrm{~K}$ condition, at the upstream of $0<x<0.2 \mathrm{~m}$ where film-cooling plays a dominant role, as the wall 
temperature is higher than that of hydrogen, the heat transfer from the wall to boundary layer make the skin friction be lower. In addition, the obtained heat from the wall can make the boundary layer transition start earlier. As shown in Fig. 18 (b), the transition initiates at $\mathrm{Re}_{x}=1.5 \times 10^{5}$ at $\mathrm{T}_{\text {wall }}=600 \mathrm{~K}$ condition while it begins at about $\operatorname{Re}_{x}=1.8 \times 10^{5}$ for both the $\mathrm{T}_{\text {wall }}=300 \mathrm{~K}$ and the adiabatic wall conditions. In addition, as illustrated in Fig. 19, at $x=0.1 \mathrm{~m}$ where the skin-friction coefficient is lowest, the temperature of the wall begins to increase for adiabatic wall condition. It is known that adding heat into boundary layer is beneficial to its transition while cooling helps to maintain its stability. Therefore, length of the transition is shorter for higher wall temperatures like $\mathrm{T}_{\text {wall }}=600 \mathrm{~K}$, while the BSL condition with $\mathrm{T}_{\text {wall }}=300 \mathrm{~K}$ experiences the longest transition process as shown in Fig. 18 (b). At the downstream of $x=0.5 \mathrm{~m}$, the temperature of boundary layer is absolutely higher than that of the wall. Thus, in this region, the amount of heat addition into flow is highest for the adiabatic wall condition, which makes its skin-friction coefficient be lower than other two conditions.

\subsection{Effect of throttling flow}

In real scramjet combustors, most of the fuel is injected into the mainstream to blend with air and generate thrust, which will make the back pressure increase in the combustor. Therefore, in order to create this high back pressure environment which is the primary characteristics in real combustor operation while decoupling the interference of main fuel combustion in core flow with the combustion in boundary layer, the air throttling method is employed to produce back pressure. So a hole which is $40 \mathrm{~mm}$ width is perforated in the upper wall near the exit at $\mathrm{x}=100 \mathrm{~mm}$. Thus, the adjustment of back pressure can be realized by modifying the mass flow rate of the throttling flow through the orifice. As shown in Table 6, another two cases with the mass flow rate of throttling flow $\dot{\mathrm{m}} \_$in $=2 \mathrm{~kg} / \mathrm{s}$ (Case 7) and $\dot{\mathrm{m}} \_$in $=3 \mathrm{~kg} / \mathrm{s}$ (Case 8) are established to investigate the effect of different mass flow rates of throttling flow. The direction of the throttling flow is set to be perpendicular to the airstream. Here for Case 7 and Case 8 the injection pressure of the orifice, $\mathrm{P}_{-}$in, is $0.3 \mathrm{MPa}$.

Fig. 20 (a) shows the distributions of the skin-friction coefficient along the lower wall for different mass flow rates of the throttling flow. Similar to the flow field analysis illustrated above, the skin friction is significantly affected by the separation flow. The value of skin-friction coefficient for Case 7 is kept the same to that of BSL condition along most part of the wall. Only at the position of the separation zone induced by the injecting throttling flow near the exit, the skin-friction coefficient drops rapidly. Similarly, at $x=0.4 \mathrm{~m}$ where the first large separation zone induced by high back pressure in Case 8 is originated, the skin friction also experiences sharp decline, these will be shown in Fig. 22. According to the analysis above, the refracted shock waves from the flame to the wall could also cause boundary layer separation, and this is the reason why the skin-friction coefficient fluctuates along the lower wall. By comparing the magnitude of the fluctuations caused by these two effects, it can be seen that the change in the skin-friction coefficient caused by back pressure is much greater than that caused by the refracted shock waves. This could also be reflected by the variation extent of skin-friction coefficient. As shown in Fig. 20 (a), any decline of skin-friction coefficient triggered by refracted shock waves is smaller than that of back pressure. Therefore, injecting throttling flow is an effective way for altering the heat release in boundary layer.

Fig. 20 (b) shows the variation of skin-friction coefficient with Reynolds number for different mass flow rates of throttling flow. Obviously, even for Case 8 with large mass flow rates of injecting airflow, as the effect of back pressures does not propagate to the auto-ignition position, the occurrence of boundary layer transition is not affected by throttling flow to a great extent. Therefore, it can be concluded that when applies the boundary layer combustion for skin-friction reduction with the main fuel combustion that is used to produce thrust together, the relative position of the boundary layer combustion relative to the combustion of the main fuel needs to be carefully considered in the flow path. The trade-off study between thermal protection and skin-friction reduction should be carried out when using this method in scramjet engine.

Fig. 21 shows the temperature contours of different mass flow rates of throttling flow. The solid black line in the figure represents the edge of the flame where the temperature is $1650 \mathrm{~K}$ and it is obvious that a lifted non-premixed flame is formed in boundary layer combustion except Case 8. When the mass flow rate of throttling flow is $2 \mathrm{~kg} / \mathrm{s}$, as the extent of back pressure increase is not large, both the flame and the flow field are almost kept the same to that of the BSL condition in most part of the flow field $(0<\mathrm{x}<1.36 \mathrm{~m})$. Only a small part of the flame is folded due to the shock wave induced by the injection of throttlingflow being incident on the flame surface near the exit. However, when the mass flow rate of the throttling flow reaches to $3 \mathrm{~kg} / \mathrm{s}$, the back pressure increases significantly and the whole flame turn to be quite twisted, this is also the reason why the skin friction coefficient is different in Case 8 shown in Fig. 20. Even worse, as shown in Fig. 21 for Case 8, from $x=0.7 \mathrm{~m}$, the high-temperature region directly expands to the wall surface at this condition. Under this situation, the heat transfer on the wall can be enhanced, which may make the heat payload to the energy management system become more serious.

Fig. 22 illustrates the Mach number contours for different mass flow rates of the throttling flow. When the mass flow rate of throttling flow is $2 \mathrm{~kg} / \mathrm{s}$, only small separation zone is formed at the lower wall near the exit due to the influence of back pressure is not large. As the injecting throttling flow reaches to $3 \mathrm{~kg} / \mathrm{s}$, however, the large disturbance to the airflow makes the induced back pressure propagates upstream to more than two thirds distance of the lower wall and a large separation zone be generated at about $x=0.62 \mathrm{~m}$. Furthermore, another three separation zones with decreasing scales are produced at the downstream as well. Under this situation, the shock train, the flame front and the separation zones together are coupled to each other, which leads the structures of flow field become quite complicated. Moreover, heat transfer on the wall is enhanced, which make the impact of heat load on the energy management system more severe. Therefore, the location of main fuel and boundary layer fuel injection should be fully considered in actual engine.

\section{Conclusion}

In this study, the effect of heat release in boundary layer on transition and skin friction were studied. The following useful conclusions were obtained:

Numerical results show that the Transition $k-k l-w$ turbulence model can effectively capture the phenomenon of boundary layer transition. When hydrogen fuel is injected into boundary layer, the flow is laminar in the region near the injector. As the film-cooling effect plays a dominant role in this region, the skin-friction coefficient firstly goes down. The occurrence of self-ignition is like a perturbation in boundary layer, which would induce the starting of boundary layer transition. Thus, the skin friction then increases. After that, when the boundary layer flow turns to be fully turbulent, the skin friction begins to decrease.

Both the position of self-ignition and the skin friction are almost not affected by changing fuel injection angles. When the injection angle along the airflow direction is increased to $30^{\circ}$, the skin-friction coefficient is slightly increased while the transition Reynolds number is relatively smaller than that of the other two angles.

The skin friction is reduced and the transition position moves downstream with the increase of the slot height. The strength of the refracted shock waves in boundary layer will be decreased with the increase of injector height, leading the range of the boundary layer separation zone would be reduced. Thus, the fluctuation of the skinfriction coefficient is slight and the variation of the skin friction along 
the lower wall becomes smoother.

At the upstream of self-ignition, if the wall temperature is higher than that of the injected fuel, the heat transfer from the wall to boundary layer can make the transition start earlier. Downstream the self-ignition location, when the boundary layer combustion plays a major role, trying to maximize the heat transfer to the wall from boundary layer is benefit for the skin-friction reduction.

As the mass flow rate of the throttling flow increases, the burning is more intense, the flame is getting twisted. Moreover, there is little effect on the occurrence of the transition by the increasing the throttling flow while the skin friction is significantly reduced. When the mass flow rate of throttling flow reaches to $3 \mathrm{~kg} / \mathrm{s}$, there were some significant fluctuations on skin-friction coefficient and the change of skin-friction coefficient caused by back pressure is much greater than that caused by refracted shock waves.

\section{Funding}

This work has been supported by the National Natural Science Foundation of China (Grant No. 51706170), China Postdoctoral Science Foundation (Grant No. 2019TQ0246, 2019M663734), the Foundation of State Key Laboratory of Coal Combustion (FSKLCCA2004), the Natural Science Basic Research Program of Shaanxi (Program No. 2020JQ-007), Foundation of State Key Laboratory of High Temperature Gas Dynamics, Foundation of State Key Laboratory of Turbulence \& Complex Systems, and Fundamental Research Funds for the Central Universities (Grant No. xzy012019053, xjh012019033).

\section{Declaration of competing interest}

The authors declare that there is no conflict of interest.

\section{References}

[1] G. Choubey, K. M Pandey, Effect of different wall injection schemes on the flowfield of hydrogen fuelled strut-based scramjet combustor, Acta Astronaut. 145 (2018) 93-104.

[2] Z. Gao, C.H. Lee, A numerical study of turbulent combustion characteristics in a combustion chamber of a scramjet engine, Sci. China Technol. Sci. 53 (8) (2010) 2111-2121.

[3] K. Sathiyamoorthy, T.H. Danish, J. Srinivas, P. Manjunath, Experimental investigation of supersonic combustion in a strut-cavity based combustor, Acta Astronaut. 148 (2018) 285-293.

[4] J.D. Anderson, Hypersonic and High-Temperature Gas Dynamics, second ed., American Institute of Aeronautics and Astronautics, New York, 2006.

[5] J. Guo, X. Geng, P. Gao, X. Ou, Recent development of drag reduction technologies via boundary layer control, Torpedo Technol. 16 (1) (2008) 1-6.

[6] H. Yang, G. Gao, Experimental study for turbulent drag reduction using A novel boundary control technique, Acta Aeronautica Astronautica Sinica 18 (4) (1997) 455-457.

[7] Z. Xu, Y. Xu, L. Wang, W. Xu, Drag reduction effect of dimple concave surface in air, Tribology 6 (2009) 579-583.

[8] Z. Sun, Progress in plasma assisted drag reduction technology, Adv. Mech. 33 (1) (2003) 87-94

[9] J. Luo, M. Xu, W. Dai, Z. Liu, Numerical simulation investigation on plasma injection for drag reduction of hypersonic vehicle, J. Astronaut. 30 (1) (2009) $120-123$.

[10] K. Satheesh, G. Jagadeesh, Effect of electric arc discharge on hypersonic blunt body drag, Shock Waves (2009) 577-582.

[11] Z. Gao, C. Jiang, Combustion heat-release effects on supersonic compressible turbulent boundary layers, AIAA J. 53 (7) (2015) 1949-1968.

[12] H. Liu, Z. Gao, Y. Tang, C. Jian, C.H. Lee, Improvement of skin friction and heat transfer prediction theory of turbulent boundary-layer combustion of hydrogen, Int. J. Hydrogen Energy 43 (3) (2017) 1937-1938.

[13] S. Wang, G.Q. He, D. Yan, Z.W. Huang, F. Qin, Analysis and reduction of skinfriction in a rocket-based combined-cycle engine flow path operating from Mach 1.5 to 6.0, Acta Astronaut. 151 (2018) 357-367.

[14] J.F. Wendt, External hypersonic aerodynamics:State-of-the-art and future perspective, Fut. Aerosp. Technol. Serv. Alliance Belg. (1997) C10.1-C10.7.

[15] W. Pfenninger, Laminar flow control-laminarization, AGARDograph 654 (1977).

[16] R.D. Joslin, Aircraft laminar flow control, Annu. Rev. Fluid Mech. 30 (30) (1998) $1-29$.

[17] R.D. Mcdaniel, R.P. Nance, H.A. Hassan, Transition onset prediction for high-speed flow, J. Spacecraft Rockets 37 (3) (2000) 304-309.

[18] J. Papp, S. Dash, Modeling hypersonic laminar to turbulent transitional flows for 3d geometries using a two-equation onset and intermittency transport models, AIAA Aerospace Sciences Meeting Including the New Horizons Forum \& Aerospace Exposition, 2006.

[19] S. Fu, L. Wang, Modelling flow transition in a hypersonic boundary layer with Reynolds-averaged Navier-Stokes approach, Sci. China, Ser. A G 52 (5) (2009) 768-774.

[20] Y.J. Yang, H.D. Ma, W.J. Zhou, Numerical research on superconic flow transition, J. Astronaut. 27 (1) (2006) 85-88.

[21] H.W. Emmons, The laminar-turbulent transition in a boundary layer-Part I, J. Aeronaut. Sci. 18 (1951) 490-498.

[22] E. Softley, Boundary Layer Transition on Hypersonic Blunt Slender Cones, (1969), pp. 69-705. AIAA Paper.

[23] S.R. Pate, Effects of Wind Tunnel Disturbances on Boundary Layer Transition with Emphasis on Radiated Noise, (1980), pp. 80-431. AIAA Paper.

[24] K.F. Stetson, Effect of bluntness and angle of attack on boundary layer transition on cones and biconic configurations, Exp. Neurol. 234 (2) (2013) 472-480.

[25] K.F. Stetson, E.R. Thompson, J.C. Donaldson, Hypersonic Layer Boundary Layer Stability Experiment on a Cone at Mach 8, Part 5: Test with a Cooled Model, (1985), pp. 89-1985. AIAA Paper.

[26] L.M. Mack, Boundary layer linear stability theory, AGARDograph 709 (1984).

[27] Z. Hao, C. Yan, Y. Qin, L. Zhou, Improved $\gamma$-Re $e_{\theta t}$ model for heat transfer prediction of hypersonic boundary layer transition, Int. J. Heat Mass Tran. 107 (2017) 329-338.

[28] J. Li, K. Pan, M. Liu, Measurement of thermal boundary and influence of combustion flame on thermal boundary of combustion chamber wall in a diesel engine, Trans. Csice 22 (5) (2004) 439-443.

[29] R.J. Stalker, Control of hypersonic turbulent skin friction by boundary-layer combustion of hydrogen, J. Spacecraft Rockets 42 (4) (2005) 577-587.

[30] J. Yu, W. Ou, K. Zhou, Mass transfer coefficients considering boundary layer reaction in oxy-fuel combustion of coal char, Fuel 124 (10) (2014) 173-182.

[31] L. Carmignani, S. Bhattacharje, S.L. Olson, P.V. Ferkul, Boundary layer effect on opposed-flow flame spread and flame length over thin pmma in microgravity, Combust. Sci. Technol. 190 (3) (2017) 535-549.

[32] C. Zhang, J. Chang, M.M. Liu, S. Feng, W. Shi, W. Bao, Effect of heat release on movement characteristics of shock train in an isolator, Acta Astronaut. 133 (2017) 185-194.

[33] Q. Chen, Numerical Investigation of Combustion in Three Dimensional Spatially Developing Supersonic Mixing Layers, Tsinghua university, Bei Jing, 2016.

[34] N.K. Madavan, M.M. Rai, Direct numerical simulation of boundary layer transition on a heated flat plate with elevated freestream turbulence, 33rd Aerospace Sciences Meeting and Exhibit, 1995.

[35] Z. Pouransari, L. Vervisch, L. Fuchs, A.V. Johansson, DNS analysis of wall heat transfer and combustion regimes in a turbulent non-premixed wall-jet flame, Flow, Turbul. Combust. 97 (3) (2016) 951-969.

[36] ANSYS FLUENT 17.0 Theory Guide, (2016).

[37] N.M. Marinov, C.K. Westbrook, W.J. Pitz, Detailed and global chemical kinetics model for hydrogen, 8th International Symposium on Transport Processes, SF, U.S.A, 1995.

[38] Z.W. Huang, G.Q. He, F. Oin, X.G. Wei, Large eddy simulation of strut enhanced mixing for supersonic combustion, J. Solid Rocket Technol. 38 (5) (2015) 664-670

[39] O.R. Kummitha, K.M. Pandey, R. Gupta, Numerical analysis of hydrogen fueled scramjet combustor with innovative designs of strut injector, Int. J. Hydrogen Energy (2018) 1-13.

[40] X. Yao, J. Tan, D. Zhang, Combustion of H2/air supersonic mixing layers with splitter plate: growth rates and transport characteristic, Acta Astronaut. 165 (2019) 401-413.

[41] X. Song, H. Wang, M. Sun, Z.C., C. Liu, J. Yu, Mixing and combustion characteristics in a cavity-based supersonic combustor with different injection schemes, Acta Astronaut. 159 (2019) 584-592.

[42] G.S. Settles, B.K. Baca, D. Williams, A Study of Reattachment of a Free Shear Layer in Compressible Turbulent Flow, AIAA Paper, 1980, pp. 80-1408.

[43] M.C. Burrows, A.P. Kurkov, An analytical and experimental study of supersonic combustion of hydrogen in vitiated air stream, AIAA J. 11 (9) (1973) 1217-1218.

[44] M.C. Burrows, A.P. Kurkov, Supersonic Combustion of Hydrogen in a Vitiated Air Stream Using Stepped Wall Injection, (1971), pp. 71-721. AIAA Paper.

[45] D. Bhatia, G. Yang, S. Jing, et al., Effects of different geometries of leading edge on boundary layer transition, 54th AIAA Aerospace Sciences Meeting, 2016, p. 1549. 